\title{
Spiritus contra Spiritum: Including Spirituality in Addiction Treatments for Recovery, a Systematic Review
}

\author{
Santiago De Ossorno Garcia ${ }^{1, *}$, Javier Martin Babarro ${ }^{1}, M^{\text {a }}$ de la Paz Toldos Romero² \\ ${ }^{1}$ Complutense University of Madrid, Spain \\ ${ }^{2}$ School of Education, Arts and Humanities, Monterrey Institute of Technology and Higher Education, Mexico
}

Copyright $\bigcirc 2017$ by authors, all rights reserved. Authors agree that this article remains permanently open access under the terms of the Creative Commons Attribution License 4.0 International License

\begin{abstract}
Spirituality had been acknowledged as a key construct to observe in the treatment and recovery from addictions. Due to the individualistic nature of the construct and overlap with religion, it is still not clear how spirituality influence treatment and recovery of individuals. Different treatments and approaches like AA philosophy or spiritual practices embrace the whole construct to obtain better outcomes in recovery for addictions. The aim of this review was to examine the effects of this construct and its relationship with recovery. A search strategy was followed to retrieve 457 scientific papers related with the matter of study. A total of 14 studies were selected and assessed for quality. Experimental and observational studies were categorised by design, and reviewed through narrative synthesis. Results showed that due to the lack of experimental research, poor quality and diverse conceptions of the construct, spiritual treatments are not more effective than other treatments whereas high levels of spirituality and spiritual practices tend to reduce the substance use outcomes and improve in other areas of recovery. From the findings reviewed which need to be considered with caution, it was concluded that implementing this construct within the therapy or approach may improve, in many cases, to achieve a successful recovery. More research is needed to determine if spiritual-related treatments have better outcomes, and some recommendations were addressed for future research, in addition to an encouragement for the inclusion of spirituality with its diversity into different domains of clinical practice.
\end{abstract}

Keywords Systematic Review, Spirituality, Recovery, Addiction, Substance Use, Twelve-steps, Spiritual Practices, Spiritual Treatments

\section{Introduction}

The eminent Carl G. Jung in his correspondence with the co-founder of Alcoholics Anonymous Bill W. [1] cited in Latin, the formula "spiritus contra spiritum" to illustrate the importance of spirituality aspects in the recovery process for those who suffer from alcoholism or other addictive behaviours. During the last decades there has been an increase of attention to spirituality, as a key construct, in clinical psychology and other health sciences. Recent findings and reviews in religion and spirituality have shown a positive relationship in mental health outcomes [2]. However, the distinction between religion and spirituality is still an on-going debate due to overlaps and multidimensionality when trying to define these two concepts [3].

Koenig, McCullough, and Larson [1, p.18], stated a clear distinction in the definitions of these two terms in their handbook: (1) Religion "....is an organized system of beliefs, practices, rituals and symbols, designed to facilitate closeness to the sacred or transcendent (God, higher power, or ultimate truth/reality)". Whereas (2) spirituality " ...is the personal quest for understanding answers to the ultimate questions about life, about meaning, and about relationship with the sacred or transcendent, which may (or may not) lead to or arise from the development of religious rituals and the formation of a community".

\subsection{Problems to Define Spirituality in Addiction}

In this review, our subject of enquiry is spirituality as a construct used by humans to give meaning to their lives. Swinton [4] gives to this concept a broad definition that allows separating spirituality from institutionalized religious structures; this open meaning will help health professionals to understand and apply spirituality in their clinical work. Therefore, the following definition is the one that will be used, "Spirituality is that aspect of human existence that gives it its 'humanness'. It concerns the structures of significance that give meaning and direction to a person's life and helps them deal with the vicissitudes of existence. As 
such it includes such vital dimensions as the quest for meaning, purpose, self-transcending knowledge, meaningful relationships, love and commitment, as well as [for some] a sense of the Holy amongst us." [5]. The aforementioned debate between spirituality and religion also influenced the field combining spirituality and addictions. A descriptive study of 265 published books and articles about spirituality and addiction found an important lack of understanding about the concept of spirituality [6]. Despite this, the author identified 13 conceptual components that were recurrent within the literature studied, in which, relatedness, transcendence, Core/force/soul and meaning/purpose were the most used in scientific literature. As the author points out, leaving spirituality unexplored and not clearly delimited may be useful but inaccurate for future development in the field.

Despite the working definition provided in the study, the difficulties and lack of consensus for defining the concept in this systematic review are accounted [7, 8, 9]. Instruments for measurement of spirituality and treatments, which include the spiritual domain, are still unclear or in development, and this conceptual barrier obstructs the research process for a systematic review. Cook [6] recommends treating the construct as multi-dimensional, and using tools such as the developed by Fetzer Institute \& National Institute on Aging Working Group [10], that proved to be useful [11].

\subsection{Relevant Findings on Spirituality and Its Importance for Recovery in Addictions}

The term recovery as such has different meanings [12] but abstinence is a common point for all of these researches [13]. Exploring the relationship that Jung accounted in his correspondence with Bill [1], many authors have suggested spirituality as an important motivator for recovery in substance-dependent people [14, 15], and it is a concept that operates in a twelve-step recovery process $[16,17,18,19-21$, 22].

Alcoholics Anonymous' twelve-step programmes recognise spirituality as key in the recovery, Miller identified [23] key elements that define twelve-step programmes as spiritual by submitting to the higher power, a regular use of spiritual practices and connectedness with the others to carry the spiritual awakening of the programme. Many of the steps are related with connecting the spiritual, forgiveness or relatedness with the self and the others [24, $25]$. Regardless of the difficulties to explore the outcomes of such treatments, due to the community setting and the nature of the program itself, there is some empirical evidence of the effectiveness of twelve-step programmes [26, 27, 2, 28].

The Tripartite model of recovery and Meta-recovery [29-31] both consider spirituality as a part of the recovery stages in addiction. This theoretical framework may invite the clinician to follow the whole person model that will acknowledge the importance of spirituality in alcoholism treatment, as well as provide a comprehensive treatment plan for patients independently of what school of psychotherapy the professionals belong to.
Some models for mental illness [32] include existential beliefs and spiritual explanations [33], specifically for addiction, some theorists consider this disorder as spiritual, mainly developed by a lack of meaning in life $[31,34]$. The existential vacuum in life $[35,36]$, leads to frustrated emotions that may be fulfilled by addictive behaviours. Wolf, Katz \& Natchson [37] observed higher existential meaning of life and lower vacuum in recovered individuals compared with those who remained addicted.

Regarding empirical evidence in the field, patient-focused researches have shown that spirituality is a positive predictor of abstinence $[38,39]$. Substance abusers found spirituality as a source of protection of the self and the others, as well as positive attitudes towards spirituality-oriented treatments [40, 41].

Cross-sectional studies have suggested that spirituality is associated with recovery and thereby with lower prevalence in substance use [42]. Another relationship found in the research was that greater spirituality levels are associated with longer recoveries and lower risk of relapse [43].

Similar to these findings, Mathew and colleagues suggested that spirituality increases after recovery [44]. Robinson, Brower and Kurtz [45] found that persons entering in treatment for alcohol problems had more life-changing spiritual experiences than the national sample. All this scientific evidence provides a framework construct for the hypothesis in this systematic review about the inclusion of spirituality in the treatment of addictions.

Moreover, including spirituality and meditation in substance use treatment reported positive results in one study with 65 adult drinkers [46]. Despite the connections between meditation practices and spirituality, there is still some debate about spirituality and spiritual practices in treatments, and for this pilot study such relationship was not considered. Nevertheless, all the treatments that include spirituality as a construct were the object of study, treating spirituality as an exposure for better outcomes in recovery for addictions and exploring possible confounders in such treatments that may be mediating the effect of this domain (Fig.1.)

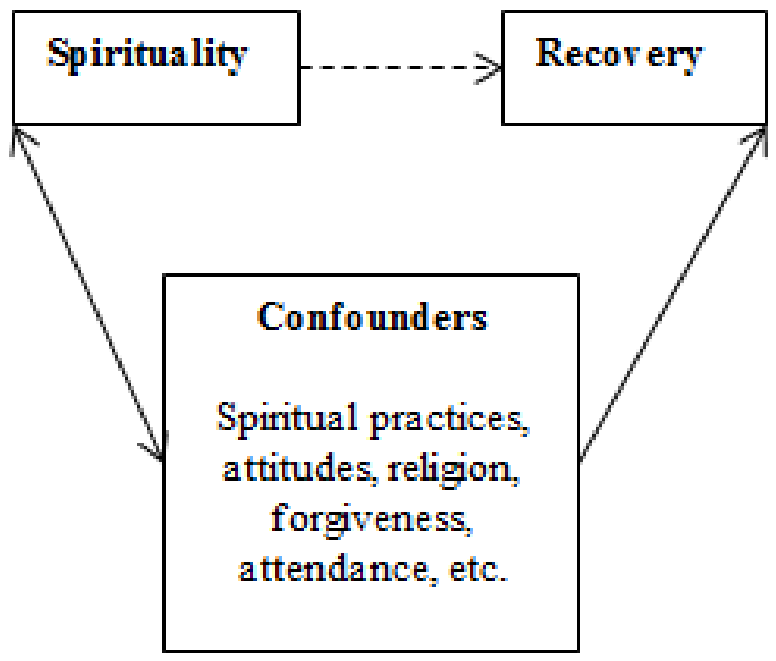

Figure 1. Model for the object of study and possible confounder 


\subsection{The Present Study}

A systematic review in this field will attempt to answer the following research questions:

Do spiritually oriented treatments provide a better outcome for recovery in addiction?

Is there a relationship between addiction recovery and spirituality?

It is hypothesised that (1): spirituality plays an important role as a domain to consider in the treatment for addictions, that might lead to better outcomes in treatment as well as mediate in the relationship for recovery from substance abuse or any other addictions.

But the question remains unclear and there is a lack of consensus to define spirituality itself. There may exist behaviours within the treatments that include spirituality that affect recovery, but it is difficult to untangle which spiritual behaviours and conceptualisations play a major role in the recovery process from addiction. The complex individual experiences of the recovery process and the lack of consensus in the spirituality research field lead to encounter difficulties to understand this construct and how it interacts with the recovery from addictions. Therefore, it is also hypothesised that (2): spiritual behaviours mediate the relationship in the recovery process from addiction and thereby a lower prevalence of substance use or addictive behaviour will exist.

\subsubsection{Aims/ Objectives}

The aim of this systematic review was to examine the effect of spirituality-related interventions for addiction problems, and explore the behaviours or variables that explain the mediation of this construct in recovery from addictions.

Although spirituality-related treatments are well recognised among clinicians and mental health professionals, a lack of quantitative research and definition of this construct remain in the field. Spirituality and spiritual behaviours, such as meditation [47], are regarded for extraordinary schema change and very often reported as key on the recovery among addicted heavily addicted users; there is a huge gap of research on how this construct can influence the recovery, but many qualitative studies examining the construct in recovered people mentioned different aspects of this type of experiences, practices [48] and education in existential/transcendental beliefs [49] as key of their recovery.

The main objective from this systematic review is, through exhaustive exploration of experimental studies that include spirituality-related treatments, verify if spirituality leads to better follow-up outcomes for substance use or addiction. Additionally we will analyse observational studies that explore the complex causal relationship of how spirituality and spiritual behaviours mediate the recovery process for individuals who suffer from substance misuse or addiction problems.
This is an attempt to fill the gap and provide additional routes, for future research and clinical studies, to explore more in depth this dimension and to understand the phenomenon of recovery and how spirituality may interact in that process. Throughout the systematic review of quantitative studies in this area of research, we will try to transform this broad construct in something measurable and scientifically rooted, despite of the transcendental and individual nature of the construct, and to provide with information about the key components of spirituality that mediate the recovery for those who had suffered addiction problems, for future clinical/research implications.

\section{Materials and Methods}

\subsection{Search Strategy}

At the first stage of the study, an exhaustive search about the research question was performed on Cochrane to confirm the absence of a systematic review about the influence of spirituality in addiction and addictive disorders. The search strategy was conducted following the recommendations of different guidelines $[50,51]$. Notice that the whole process of this systematic review followed these two guidelines.

The systematic electronic search strategy was conducted in three databases in December 2012:

(1) PsycInfo (American Psychological Association),

(2) ISI Web of Knowledge (Thomson Reuters)

(3) Scopus (SciVerse).

The search terms used in the electronic search were "spirituality" AND "recovery" AND "addiction" OR "substance misuse". For better detection of relevant articles we also added "treatment outcomes" in order to identify clinical trials and interventions, no additional complex algorithmic searches were included in the study on account of lack of papers identified in the databases.

The search was conducted with no language restrictions during the systematic search strategy, but only papers in English were reviewed. The electronic search screened for articles since 1975 in all databases, following the recommendation by Cook [6].

\subsection{Study Selection and Characteristics}

Overall 457 references were identified from the combined search strategy, 378 references were screened by title and abstract. From this vast array of references, 40 studies were not retrievable, and 209 were excluded for not being related with spirituality or not being peer review journals or articles. 129 references were retrieved as full text articles and assessed for eligibility for the study. A flow-chart of the search (Fig. 2) illustrates this process. 


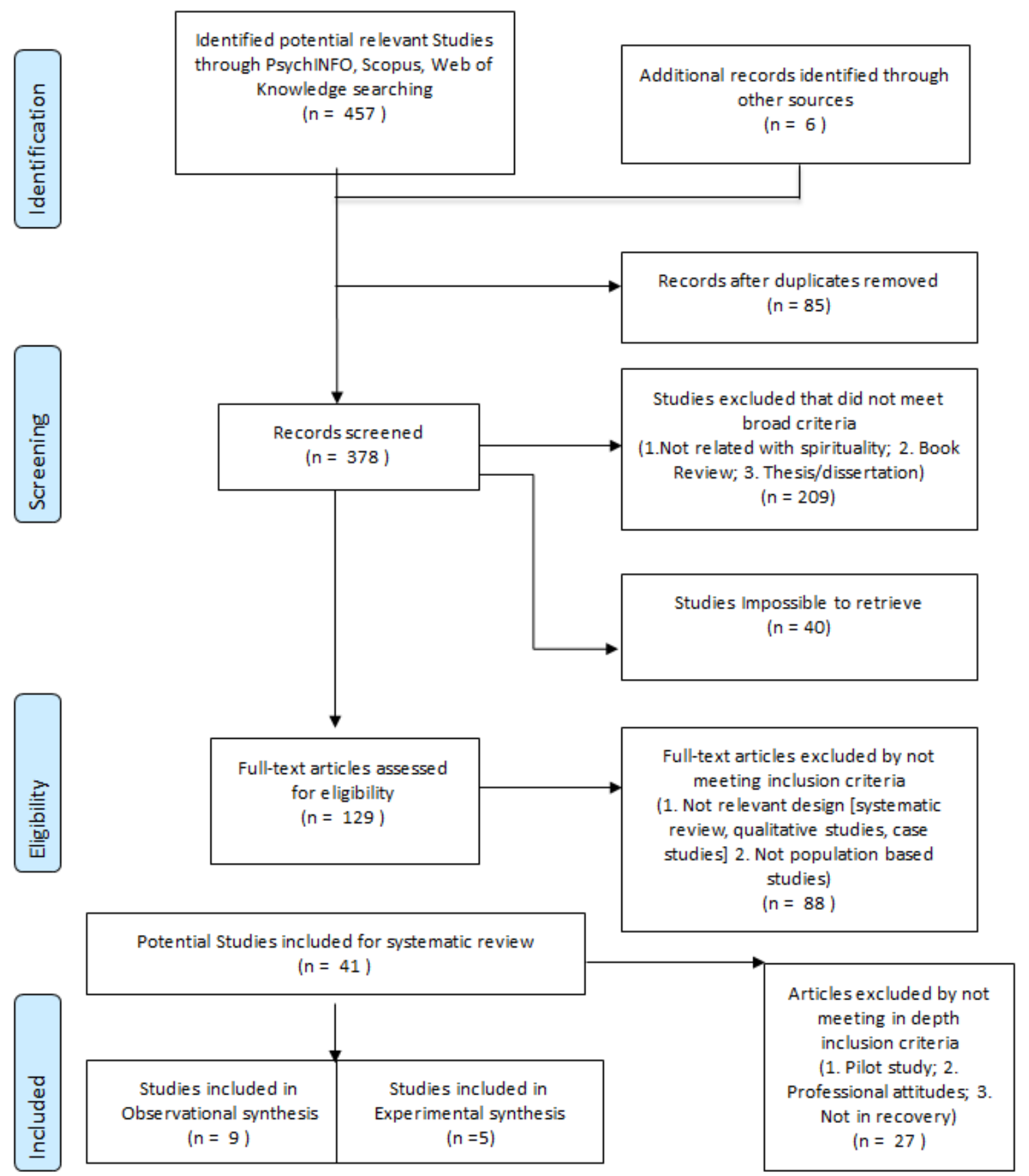

Figure 2. Quality of studies reviewed

\subsubsection{Inclusion/Exclusion Criteria}

For the inclusion and exclusion criteria the recommended application of PICOS was performed:

(1) The population covered adults of at least 18 years old, no restrictions in geography, who meet the criteria for substance use disorder DSM-IV and DSM-III; any other addiction such as gambling or sex addiction were also considered; Self-report or historical dependence of addiction were included too.

(2) Interventions where the spiritual domain is included, techniques of spiritual traditions like meditation, and where a spirituality approach is used in treatment. Twelve-step programs, Spiritual Guidance, 3-S Schema, Alcoholics, Narcotics \& Gambling Anonymous. Also those studies that consider spirituality as a multi-dimensional construct [10];

(3) As outcome, recovery was considered. Long-term outcomes or follow-up assessment (3, 8, 12 and 18 months), give us an indicator for recovery, other indicators being substance abuse self-reported scales and biological samples of abstinence. Different outcome measures related with spirituality were included, for instance, spiritual/religious practices, attendance to spiritual meetings, life oriented measures, spiritual well-being and other outcomes that are related with spirituality; 
(4) Due to the lack of information about the topic considered RCT, Controlled Trials, Cross-sectional Studies, Longitudinal studies, Case-Control studies, and Cohort studies were considered.

Whereas exclusion criteria enclose: Population under 18 years old, which are less prone to understand spirituality in their stage of development. Non population-based studies, because theoretical information is not relevant for answering the research question and it was already synthesised in the past, strictly religious oriented treatments, pilot studies, studies focusing exclusively on treatment seekers or just during treatment, studies that do not address recovery process, and treatments and therapies in which spirituality is not included or only partially addressed. Case studies, systematic reviews and qualitative studies were excluded. The main reasons for exclusion were based on providing to the reader an empirical evidence of the quantitative data available for the relationship between spirituality and addiction.

\subsection{Quality Assessment}

For assessing the quality of the studies included in the review, the Quality Assessment Tool for Quantitative Studies developed at McMaster University, Canada, from the Effective Public Health Practice Project (EPHPP) was selected [52]. Despite the limitations for the assessment of community-based interventions of this tool, it was considered the most suitable to be used in systematic reviews about effectiveness of treatments [53], and also allows the assessment of the different study designs that were included in this systematic review such as case-control studies, controlled trials, cohort studies and cross-sectionals designs. This tool for assessing the risk of bias in studies had been validated in the past showing good reliability between the agreements of reviewers [54]. The findings of the studies were collected with the results of the quality assessment tool used for the quantitative studies found for this review. Note that one of the studies contains two clinical trials in the same article; the assessment tool was performed for each.

\subsection{Heterogeneity and Risk of Bias in Included Studies}

Findings of those articles, which were globally rated as weak by the quality assessment tool, were interpreted with caution to reduce the possible risk bias in the study; the strength of the quality in each domain was taken into account in the results section. Global rates from the Quality assessment tool (see Fig 3) showed high proportion of weak global quality $(57.1 \%)$ representing a high risk of bias for the whole review [55], 5 studies were identified as moderate $(35.7 \%)$, and only one study assessed as strong quality (7.2\%). These findings address the aforementioned problematic regarding the lack of research in the art, and encourage for future studies to increase the quality of research in this matter. Due to the heterogeneity of the reviewed studies, a meta-analysis may add more bias to the findings; different designs, outcomes and statistical analyses that differ in nature, hinder the theoretically reliable meta-analysis.

Therefore, a narrative synthesis combined with systematic data extraction for each study will allow the reader to understand the current state of spirituality in substance abuse and addictions in scientific literature.

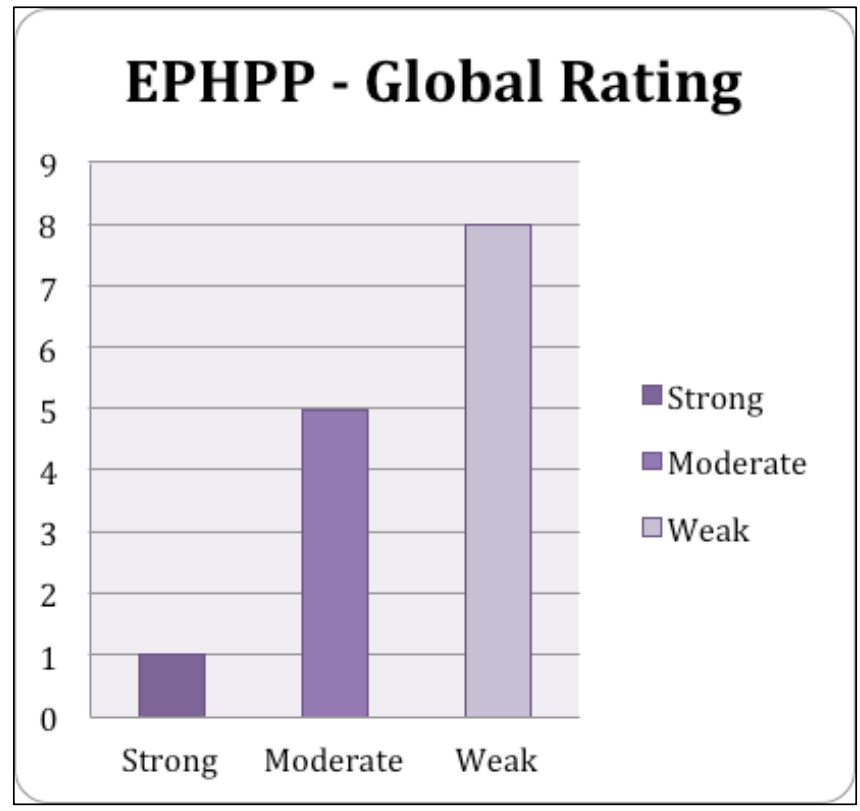

Figure 3. Quality of studies reviewed

\subsection{Data Extraction and Synthesis}

The results of the data extraction for this systematic review are presented in structured tables, followed by a comprehensive narrative synthesis for each study, divided in experimental and observational studies. These two broad categories were divided by study design, in order to address the implications of the findings and bias to answer the research questions of this review.

The previously acknowledge heterogeneity of design studies and statistical results, forced the researcher to synthesise and extract the data in tables following an iterative process, after performing and taking into account the quality assessment for each study. The iterative process for data extraction was carried out following a quality assessment framework that was previously piloted, similar to those described by Thomas and colleagues [54], with more in-depth synthesis, including statistical analysis performed in the study or explanatory models created in the studies by structural equations. For the narrative synthesis a more interpretative and flexible framework developed for this review, following previous examples of this more interpretative approach [56, 57], allows the reader to understand the gaps and provide evidence of the existing literature for spirituality and addictions for future research and intervention development, in which, the relevant themes 
and concepts were noted down, after the data extraction and synthesis, as a comprehensive guide for the reader that addresses the key findings, bias, and interpretations in the aforementioned articles.

The existing knowledge about this subject and the systematic search, both reflect a lack of clinical trials and how implementing spirituality in substance misuses and addiction treatments or interventions is rare. On the other hand, there are different longitudinal, cross-sectional, prospective and retrospective studies that reflect the relationship between substance consumptions and levels of spirituality, or changes experienced by the population aimed in this review.

Studies, quality, population, interventions, substance use measures outcomes, spiritual measures outcomes, statistical analysis results and findings are summarised for each article in tables 1, 2.1 and 2.2. The narrative synthesis is presented for each article, divided by study design; the effects of the quality of each study on the effectiveness of the data collected are discussed and reviewed. Note that in observational studies section, results are divided in cross-sectional and non-cross-sectional design, due to the nature of the relationships of this type of design.

\section{Results}

\subsection{Description of Studies}

A total of 14 studies were identified, classified and synthesised for this systematic review. Five experimental designs (Randomized Controlled trials $n=1$; Controlled Clinical trial $n=3$; Quasi-experiment $n=1$ ) were identified, that include spiritual measures to test the influence on treatment outcomes of substance misuse, all with at least three months follow-up measures for recovery. These designs allow the researcher to observe the changes after specifically addressed as spiritual interventions approaches for addiction (12steps meetings and programmes, spiritual guidance) with the exception of Heinz, et al. [58] in which study the nature of the intervention was not specified, but an assessment of spirituality linking treatment outcomes was performed.

Note that in the final phase of inclusion, seven experimental design studies were identified but excluded for not being quantitative or being pilot/preliminary studies. That reflects the underdevelopment "state of the art" of spirituality treatments nowadays. Miller and colleagues [59] account the absence of prior clinical trials in the field. The unique quasi-experimental study included in the review that falls in between of observational and experimental characteristic was included as experimental due to the uncontrolled effect of twelve-step meetings in the sample as spiritual treatment or intervention.

The remaining 9 studies included in the review were identified and classified as observational studies, measured at one or more specific points time, but without systematic evaluation of spiritual interventions, the majority of studies included are classified as cross-sectional studies $(n=5)$ of substance abuse population that are in recovery, exploring the relationship with a wide range spirituality measures and outcomes for relapse prevention or substance use. A few of them treated spirituality as multi-dimensional; others used just one scale of R/S attitudes. The rest observational designs of prospective and retrospective nature that were included in the review (Case-Control studies $n=2$, Cohort studies $n=1$ and longitudinal studies $n=2$ ), allow for a better understanding about the causal factor and relationships across time that cross-sectional designs are lacking.

\subsection{Review of Experimental Studies}

\subsubsection{Experimental Design}

Kelly et al. [60] conducted a research within the project MATCH [61]. MATCH studied whether treatment should be uniform or assigned to patients with alcohol problems based on their heterogeneity. It was performed in the United States and financed by the National Institute on Alcohol Abuse and Alcoholism (NIAAA). Study design was a Randomised Controlled Trial (RCT) where subjects were randomly allocated to Cognitive behavioural Therapy, Motivational Enhancement Therapy or twelve-step facilitation program. For the last one mentioned, AA philosophy, hence a spiritual approach for the treatment was included, as well as, encouragement to attend the meetings. On the other hand, Study 1 [59] was randomised, but the randomisation was not explained in the article and, due to that, after the quality assessment it was characterised as a controlled clinical trial, in which the treatments allocated were Treatment as usual (TAU), and one program of 12 sessions of spiritual guidance (SG). So all the participants received the TAU and some through randomisation also received $\mathrm{SG}$. All the patients in this study received a detoxification treatment at the beginning of the study, with sample urine tests. Similar to Kelly et al. [60], Zemore [61] used participants for a clinical trial comparing day hospital and community residential treatment with randomised and non-randomised arms for chemical dependency. From this trial they retrieved and monitored the participants who attended to what they called "informal treatment", which means twelve-step meetings. In contrast with the Project MATCH where one of the groups of the trial was the twelve-step facilitation, in the study of Zemore [61], non-specific group of the trial was genuinely spiritual or allocated to spiritual treatment or condition, whereas all were monitored for informal treatments like twelve-step meetings. Heinz et al. [58] study derived similar data from clinical trial that was originally intended for other purposes (obtaining pilot data for craving questionnaires), but in this study all participants underwent an individual outpatient drug counselling program weekly, and detoxification treatment with sample urine test (21 days of additional methadone treatment was offered for opiate 
dependants), no randomisation procedures were conducted, and the intervention delivered was not spirituality-related. On the contrary a self-reported measure of twelve-step attendance was reported containing surprisingly low rates for this population (only $11 \%$ of the sample).

The last experimental design was a quasi-experiment conducted by Carter [49] in where two groups (recovery and unrecovered) recruited in twelve-steps programs where assessed with B-PRPI as an indicator of spiritual practices involvement, but those in the unrecovered group acknowledged an history of relapses and B-PRPI scores when compared in a descriptive manner with the number of relapses and years sober in each group. These results must be interpreted carefully; the design and selection of the participants (selected sample) of the study may produce bias between these two groups.

There is large impairment in sample sizes between clinical trials $(n=1726 ; n=537$ vs. $n=64 ; 63$ and $n=169)$, all seemed representative of this specific population of study, whereas studies might present some population bias, in terms of gender and ethnicity, as well as religious background. The salient biases from the clinical trials regarding the population, are summarized in the table 2, also this table notes if demographic variables were controlled and the control method used. The selection procedure and the criteria were similar, all the studies represent a population of addiction (process and chemical addictions) with the exemption of the project MATCH study [60] in where all the participant where dependant of alcohol exclusively. Studies of Miller et al., [59], Zemore [61], Heinz and colleagues [58] and Carter [49], and colleagues had some restrictions in the area of selected subjects who participate in their studies. Also a predominant amount of males is noticeable in the three studies, and there is no report of gender differences in Zemore's sample [61]; these facts can also bias this review in order to extent this conclusion to the aimed population.

The follow-up was similar, due to the nature of the quasi-experimental design only one follow up was taken, also in the study of Heinz, et al. [58] a short 3 months follow-up may be considered an early point in time to assess recovery, but noting that the treatment outcomes were related with consecutive negative urine samples, a longer follow-up would increase considerably the costs for this research. Kelly et al. [60] 15-month follow-up allowed conducting a lagged mediational analysis for observing the relationship between the predictors and predict and, without the need of being contemporaneous, note that it is a retrospective study and because of that, blinding for research was not possible. The study 1 from Miller et al. [59] did not reflect any blinding. They used ANOVA for time and group, and the interaction of both is meant to show the effects of the SG intervention.

All clinical trials observed better outcomes after treatment for substance use, with differences in findings that can be attributed to the methodological nature of the study, but with diversity in quality assessment scores (see Table 1) implications, and also the interventions applied in some studies were not spirituality-related (See Heinz et al. 2007 in
Table 1) or were not controlled (12-steps self-self report attendance).

An in-depth interpretation for Miller et al. [59] study showed that there are no differences between treatments (TAU \& SG) in the substance use outcome ( $p>.20$ ), they only found significant effects of increase in the percentage of days abstinent (PDA) at 4-month follow-up $(F(1,52)=31.04$, $\mathrm{p}<.001)$. For the mediational analysis performed in Kelly et al. [60], the AA attendance was related with less alcohol use; note that in this study the other treatments were not compared. In regards to spirituality measures, in SG intervention as well as in the whole study there was no significant differences in spiritual variables $(F(1,37)=3.00$ $\mathrm{p}=.091)$, note also that the adherence to $S G$ treatment was very low ( $57 \%$ considered treated $\mathrm{M}=4.8$ sessions) (see Table 1). On the contrary, Kelly and colleagues [60] found an increase of the $\mathrm{S} / \mathrm{R}$ in relationship with AA attendance, relevant confounders were controlled, and ethnic minorities scored more in S/R. For aftercare subjects, $28 \%$ of the percentage of days abstinent was explained by the levels in $\mathrm{S} / \mathrm{R}($ Mack $\mathrm{Z}=4.38, \mathrm{p}<.01)$ with a $24 \%$ direct effect of AA attendance in the drinks per drinking day of the subjects was explained by $S / R$ (Mack $Z=-3.97, p<.01$ ). For better understanding, the fact that those subjects who attended AA reported less drinks when they drank during the treatment, was explained to some extent by the levels of S/R.

Sarah Zemore [61] found better outcomes in her study in relationship with abstinence. Higher odds were associated, after conducting a logistic regression, with an increase in religious behaviours and experiences from the baseline at the 12-months follow-up, OR=1.11 (95\% CI [1.06, 1.17]), $\mathrm{p}<0.001$. To support this results a chi-square was performed between the baseline and follow-up, and found that those who reported spiritual awakening in that period of time were more likely to report total abstinence, $\chi^{2}(1.507)=26.48$, all relevant confounders were controlled, and an important finding is that baseline spirituality scores in the RBB did not predict treatment outcomes. In other words, the spiritual change or experience during the treatment may be related with better outcomes of abstinence. Increases in twelve-step involvement from baseline to follow-up were also associated with higher odds of abstinence, OR=8.86 $(95 \% \mathrm{CI}$ $[4.46,16.92]), \mathrm{p}<.001$, and twelve-step involvement was also associated with increases in RBB scores and higher odds of spiritual awakening (for odds ratio see Table 1). At the same time those who did not report changes or decreased their involvement in twelve steps involvement were much less likely to report abstinence (at $42 \%$ ) than those who reported an increase in their involvement (at 72\%). Finally they conducted a test for mediation using hierarchical regression, two models were implemented, when they included the twelve-step involvement change variable, the odds of abstinence in the model increased significantly, $\mathrm{OR}=9.35$ $(95 \% \mathrm{CI}[4.48,18.24]), \mathrm{p}<.001$. At the same time RBB change scores and spiritual awakening, which can be interpreted as variables for spiritual change, when those variables were included in the model dropped the effect of 
twelve-step involvement change, OR=7.50 (95\%CI [3.76, 14.95]) \& $\mathrm{OR}=6.54 \quad(95 \% \mathrm{CI}=[3.24,13.22]), \mathrm{p}<\quad .001$, verifying, to some extent, the mediation of these spirituality related variables in the treatment outcomes.

Regarding the other two experiments, Heinz, et al. [58] \& Carter [49], their findings also support the hypothesis of this review, showing better outcomes in substance misuse and addiction. Heinz, et al. [58] measured spiritual variables and found that increases in INSPIRIT scores predict more negative samples for opiates and cocaine in the participants of the study, as well as through ANOVA analysis, finding an association between spiritual practices and the treatments outcomes. The reader needs to take into consideration that, for this experiment, the treatment applied to the participants was based in 12 week counselling sessions and there is no reference for the inclusion of any spiritual approach in such treatment.

Finally, the findings of the quasi-experimental design showed differences between groups (recovered Vs. unrecovered) after they conducted a t-test (see Table 1), but this should be interpreted with caution due to the implicit characteristics in each group (differences were noted in gender, B-PRPI, sobriety, attendance to twelve-step, psychiatric diagnosis, and number of relapses). Even after comparing the descriptive statistics between number of relapses or years sober with the scores of B-PRPI, it is expected that this descriptive results were in concordance with the hypothesis due to selection bias of each group in the study, in where recovered group seemed different in nature due to the selection criteria, as a criticism if we select a sample with a history of relapses and compare with other sample that acknowledges recovery and better outcomes in the beginning, it is likely to find overall differences in outcomes between groups. Also Carter [49] assumed that high scores in B-PRPI were indicative of higher level of participation in spiritual practices, even though the Brown-Peterson Recovery Progress Inventory had been validated as a measure for spiritual practices and spirituality [63] a self-report of amount of spiritual practices among participant, does reinforce this finding. The nature of the groups and the descriptive comparisons for the mean scores of B-PRPI in the number of relapses and years sober seems like an insufficient analysis to support his findings. On the other hand his findings are in accordance with the rest of experimental studies reviewed, in where spiritual scores where related with better long-term recovery outcomes.

There is a tendency in experimental studies to confirm our first hypothesis, but the quality of studies varies, also the lack of randomisation or blinding for each study might bias our conclusion. Zemore [61] explored change variables in her experiment, further retrospective and prospective designs commented in next section might help to the reader to support and understand the causal relationship between spirituality and recovery outcomes found in these experiment reviews. 
Table 1. Summary of the findings for Experimental Studies

\begin{tabular}{|c|c|c|c|c|c|c|c|}
\hline \multirow[b]{2}{*}{ Rating/Design } & \multirow[b]{2}{*}{ Study/Country } & \multirow[b]{2}{*}{ Sample Characteristics } & \multirow[b]{2}{*}{ Follow-up } & \multirow[b]{2}{*}{ Interventions } & Outcomes & & \multirow[b]{2}{*}{ Findings } \\
\hline & & & & & $\begin{array}{l}\text { Substance } \\
\text { use/relapse }\end{array}$ & Spiritual Measures & \\
\hline$++/ \mathrm{RCT}$ & $\begin{array}{l}\text { Kelly et al. } \\
\text { (2011) } \\
\text { USA }\end{array}$ & $\begin{array}{c}\mathrm{n}=1726 ; \\
\text { Outpatient }[\mathrm{OP}](\mathrm{n}=952,72 \% \text { male), } \\
\text { Aftercare }[\mathrm{AC}](\mathrm{n}=774,80 \% \text { male)} \\
\text { Age }=18+; \\
\text { Criteria for DSM-III-R (interview) } \\
\text { for alcohol dependence }\end{array}$ & $\begin{array}{c}3,6,9,12 \text { and } \\
15 \text { months }\end{array}$ & $\begin{array}{c}\text { Randomly allocated } \\
\text { to: } \\
\text { CBT, MET, TSF }\end{array}$ & DDD, PDA & $\begin{array}{l}\text { AA attendance; } \\
\text { S/R score (RBB } \\
\text { scale) }\end{array}$ & $\begin{array}{c}\text { Mediation model analysis found: } \\
\uparrow \text { AA attendance } \downarrow \text { alcohol use; younger age \& prior } \\
\text { treatments } \uparrow \text { DDD; } \\
\uparrow \text { AA attendance } \uparrow S / R \text { score; Minority ethnic patient } \\
\uparrow S / R \text { than White [only in OP]; AAxR/S strongly } \\
\text { associated with } \uparrow S / R \text { among lower } S / R \text { at baseline } \\
(\mathrm{b}=-0.0029 ; \mathrm{p}=0.0175 ; \beta=-0.008 \text { ) for AC and } \\
(\mathrm{b}=-0.0023 ; \mathrm{p}=0.0115 ; \beta=-0.06 \text { ) for OP. } \\
\text { Lagged analysis found: } \\
\text { For AC } 28 \% \text { of PDA was explained by } \mathrm{R} / \mathrm{S} \text { (Mack } \\
\mathrm{Z}=4.38, \mathrm{p}<0.01) ; 24 \% \text { Direct effect of AA on DDD } \\
\text { was explained by } \mathrm{S} / \mathrm{R} \text { (Mack } \mathrm{Z}=-3.97, \mathrm{p}<0.01) \\
\text { For OP } 14 \% \text { of PDA was explained by } \mathrm{R} / \mathrm{S} \text { (Mack } \mathrm{Z}= \\
3.35, \mathrm{p}<0.01) ; 13 \% \text { Direct effect of AA on DDD was } \\
\text { explained by } \mathrm{S} / \mathrm{R} \text { (Mack } \mathrm{Z}=-3.31, \mathrm{p}<0.01 \text { ) }\end{array}$ \\
\hline$+/ \mathrm{CCT}$ & $\begin{array}{l}\text { Miller et al. } \\
(2008) \\
\text { Study } 1 . \\
\text { USA }\end{array}$ & $\begin{array}{c}\mathrm{n}=160 ; \\
\mathrm{n}=64 \text { finally enrolled Age }=18+; \\
(40 \% \text { male); } \\
\text { Criteria for DSM-IV substance } \\
\text { dependence; } \\
\text { Hispanic (50\%); non-Hispanic } \\
(35 \%) ; \text { Native American (12). } \\
\text { Confounder controlled and measured } \\
\text { at baseline (Age, Gender, Ethnicity, } \\
\text { substance abuse and } 19 \\
\text { psycho-spiritual variables). }\end{array}$ & $\begin{array}{l}\text { 4, } 8,12 \\
\text { months } \\
\text { follow-up }\end{array}$ & $\begin{array}{c}\text { Polydrug } \\
\text { detoxification - } \\
\text { SG or SG+TAU }\end{array}$ & $\begin{array}{c}\text { Substance use } \\
\text { outcomes (PDA) } \\
\text { Anxiety = STAI; } \\
\text { Depression= BDI; } \\
\text { Self-esteem=[SEI] } \\
\text { inventory }\end{array}$ & $\begin{array}{c}\text { BMMR with special } \\
\text { interest in= Daily } \\
\text { Spiritual } \\
\text { experiences, } \\
\text { Meaning in life, } \\
\text { Private religious } \\
\text { practices. }\end{array}$ & 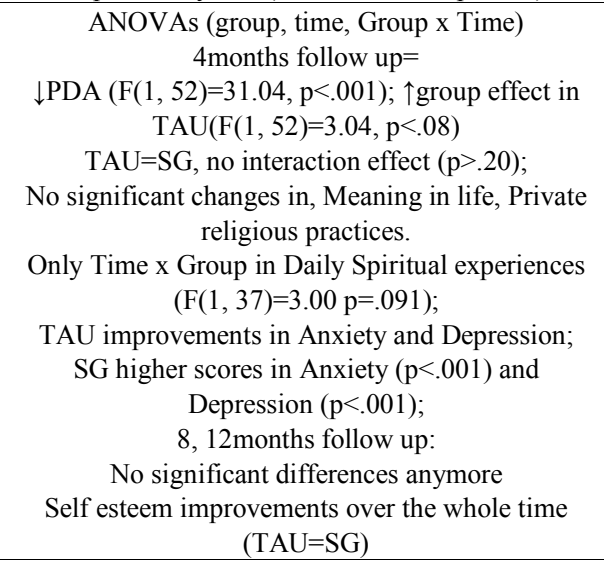 \\
\hline
\end{tabular}




\begin{tabular}{|c|c|c|c|c|c|c|c|}
\hline$++/ \mathrm{CCT}$ & $\begin{array}{c}\text { Zemore, } \\
(2007) \\
\text { USA }\end{array}$ & $\begin{array}{l}\mathrm{n}=537 \text {, initially treatment seekers } \\
\text { from a clinical trial of cost between } \\
\text { residential and day hospital } \\
\text { treatments for chemical dependency. } \\
\text { Majority of drug dependence } \\
\text { diagnosis, to different substances. }\end{array}$ & 12 months & 12-Steps & $\begin{array}{c}\text { Substance use } \\
\text { outcome }= \\
\text { self-report } \\
\text { (30-days abstinent) }\end{array}$ & $\begin{array}{c}\text { RBB;12-Step } \\
\text { Involvement; } \\
\text { Spiritual awakening; } \\
\text { Spiritual change. }\end{array}$ & $\begin{array}{c}\text { Logistic Regression: } \\
\uparrow \text { religious behaviour/experiences associated with } \\
\text { abstinence } \\
(\mathrm{OR}=1.11[95 \% \mathrm{CI}: 1.06-1.17]), \mathrm{p}<0.001 \\
\chi^{2}(1,1507)=25.48, \mathrm{p}<0.001 \text { : Spiritual awakening } \uparrow \\
\text { likely to remain abstinent } \\
12 \text { Involvement } \uparrow \text { odd of abstinence }(\mathrm{OR}= \\
8.89[95 \% \mathrm{CI}: 4.64-16.92]), \mathrm{p}<0.001 \\
12 \text {-Step Involvement associated } \uparrow \mathrm{RBB} \text { scores } \\
(\mathrm{B}=0.29, \mathrm{p}<0.001) \& \uparrow \text { Odds of spiritual awakening } \\
(\mathrm{OR}=34.15[95 \% \text { CI: } 14.67-79.49, \mathrm{p}<0.001]) \\
\text { Hierarchical Regression } \\
\text { Model } 1 \text { : Confounder controlled } \\
\text { Model 2: Spiritual change variables } \\
\downarrow \text { odds ratio for association between abstinence and } \\
12 \text {-step involvement, when add spiritual change } \\
\text { variables } \\
(\mathrm{OR}=6.54[95 \% \mathrm{CI}: 3.24-13.22]) .\end{array}$ \\
\hline$+++/ \mathrm{CCT}$ & $\begin{array}{l}\text { Heinz, et al. } \\
\text { (2007) } \\
\text { USA }\end{array}$ & $\begin{array}{c}\mathrm{n}=169 ; \text { sample extracted from a } \\
\text { clinical trial at an outpatient } \\
\text { treatment; } \\
\text { Male }(71 \%) ; \\
\text { African American }(66 \%) ; \\
\text { Protestants }(56 \%) \\
\text { Catholic }(24 \%) ; \\
\text { Seeking treatment for cocaine and } \\
\text { opiate use. }\end{array}$ & 3 months & $\begin{array}{l}12 \text { weeks } \\
\text { Outpatient } \\
\text { Counselling } \\
\text { And } 21 \text { days } \\
\text { methadone detox }\end{array}$ & $\begin{array}{l}\text { Cocaine-Negative } \\
\text { urine; } \\
\text { Opiate-negative } \\
\text { urine; days of } \\
\text { retention in } \\
\text { treatment. }\end{array}$ & INSPIRIT & $\begin{array}{c}\text { ANOVA: } \\
\uparrow \text { INSPIRIT scores predict } \uparrow \text { cocaine-negatives } \\
(\mathrm{r}=.016, \mathrm{p}<0.04 \text { ) and } \uparrow \text { opiate-negatives } \\
\text { Spiritual orientation associated with: } \uparrow \text { consecutive } \\
\text { cocaine-negatives }(\mathrm{F}[3,165]=3.16, \mathrm{p}<0.03 \text { ) } \\
\text { Amount of spiritual practices associated with: } \\
\uparrow \text { Cocaine-negatives } \\
\text { (F }[3,165]=6.88, \mathrm{p}<0.001) \\
\uparrow \text { Opiate-negatives } \\
(\mathrm{F}[3,165]=5.64, \mathrm{p}<0.001) \\
\uparrow \text { Treatment retention } \\
(\mathrm{F}[3,165]=2.89, \mathrm{p}<0.04) \\
\end{array}$ \\
\hline$+/ \mathrm{QE}$ & $\begin{array}{c}\text { Carter, (1998) } \\
\text { USA }\end{array}$ & $\begin{array}{l}\mathrm{n}=63 \text {; Group } 1(\mathrm{n}=33) \text { : Female }(33 \%) \\
\text { In recovery for } 1+\text { year. } \\
\text { Recruited in } 12 \text {-steps } \\
\text { Group } 2(\mathrm{n}=30) \text { : Male }(93 \%) \\
\text { History of relapses, less } 1 \text { year sober. } \\
\text { Recruited } 12 \text {-steps and outpatient }\end{array}$ & None & 12 steps meetings & $\begin{array}{l}\text { Sobriety; Number } \\
\text { of relapses }\end{array}$ & B-PRPI & $\begin{array}{c}\text { T-test revealed significant differences between } \\
\text { groups [t }(61)=5.46 . \mathrm{p}<0.0001)] \\
\uparrow \text { B-PRPI scores in group1 had } \uparrow \text { term recovery and } \downarrow \\
\text { number of relapses. } \\
\uparrow \text { B-PRPI scores }=\uparrow \text { participation in spiritual } \\
\text { practices. }\end{array}$ \\
\hline
\end{tabular}

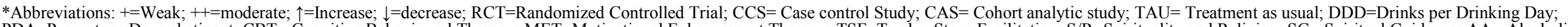

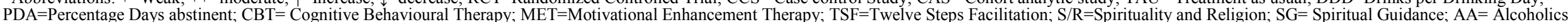
Anonymous; OR=odds ratio; CI=Confidence Interval; LTR= Long-term residential; STI=short-term inpatient; ODF=Outpatient drug free; OMT=outpatient methadone treatment; ASI=Addiction Severity Index. 


\subsection{Review of Observational Studies}

\subsubsection{Cohort Study Design}

In the study 2 by Miller et al. [59], due to the failure of the first trial, they conducted a new one with more subjects $(n=80)$ and a cohort design. All sample confounders were controlled, but no randomisation or blinding was conducted (see Table 1, for quality score). Group x Time repeated measures ANOVA was conducted for the analysis. They found a significant reduction in substance use over the time for both treatments SG and TAU ( $<<.001)$, but no significant differences were found between treatments. More in depth, Chi-Square test for PDA found a positive difference for SG but was not significant in comparison with TAU ( $>$ >.05).

The follow-up was for 3 and 6 months, the authors hypothesise that one of the failures of the trial could be caused because the intervention was offered too early for the recovery process, since spiritual growth is at the top of Maslow's pyramid of needs [64], which means that maybe a longer time is required to foster spirituality. Therefore, increased Daily Spiritual experiences (F $(1,53=4.146 \mathrm{p}=$. 047) were found in SG in comparison by TAU in 3 and 6 months ( $F(1,47=4.924 \mathrm{p}=$. 04) follow-up, but did not mediate the relationship between SG treatment and PDA outcome in any follow-up $(\mathrm{p}=.875 ; \mathrm{p}=.664)$.

\subsubsection{Case-control Design}

Sterling et al. [65] conducted a case control study in the United States with an original sample of $n=278 ; 36$ subjects who reported relapse after 3 months follow-up were paired with other 36 that did not relapse at that point, all confounders were controlled by matching. The history of addiction was $\mathrm{M}=22.90$ years of history drinking. There are some population biases due to ethnicity ( $94.4 \%$ Caucasian) and gender (61\% male).

The follow-up was only after 3 months, with measurements at the intake of treatment and at end-of-treatment. The treatment is addressed in the article as in-treatment, so an attempt to specify the nature of the treatment was performed in contacting the authors without response, which means that we are unable to analyse in which extent spirituality was addressed here.

On the other hand, this study showed the best validity for spiritual measurements using a wide range of instruments (DSES, BMMRS, RSCOPE, SEI, INSPIRIT) to explore the changes of this multi-dimensional construct during the time. The findings of the study revealed an in-treatment spiritual growth through one item of BMMRS, $(83 \%$ reported spiritual component to treatment was considerably or extremely important); even if the percentage is high, these are just two-way repeated measures for one-item analysis from one of the tests applied.

Through paired t-test analyses they found an increase of spiritual levels, no matter the outcome of substance use $(\mathrm{Ms}=19.43 \pm 4.65$ and $21.25 ; \mathrm{t}(71)=4.51, \mathrm{p}<.001)$, showing the fact of a spiritual awakening when people start the treatments for recovery in addictions. They conducted ANOVAs to observe the maintenance effect of these levels during the time, and found that in 3 months follow-up a significant decrease in SEI for those who relapse was found $(t(31)=3.01, p<.01)$, and significant interaction effects of DSES $(p=.08)$ and SEI $(p=0.3)$. The reason, to which the author attributes these differences to just some and not all of the tools, is the reliability of the instruments. One main limitation addressed by the authors is the self-report measures for substance use outcome. Also the effects of the in-treatment were not addressed or compared with spiritual levels, and finally the correlation nature of the data does not allow for interpretation of causality.

Similarly, the other case-control study reviewed [66] have considerable size sample $(n=708)$ from United States national evaluation of treatment effectiveness, the Drug Abuse Treatment Outcome Studies (DATOS) funded by the National Institute on Drug Abuse (NIDA) observed populations that were abusing cocaine and HIV/AIDS-exposed that entered in treatment between 1991-1993, the project included a 5 year follow-up. Flynn and colleagues [66] analysed the reasons for recovery of participants in the study, they enrolled in 45 treatment programs in eight cities across the United States. These 45 programs were classified in 4 treatment modalities (see interventions in Table 2.1), outpatient drug-free (ODF) treatment included CBT, twelve-step and other wide range of therapeutic approaches. In relationship with the sample characteristics, it is salient the percentage of African American (56\%) within the sample. Due to the retrospective nature of the design, participants were divided in recovered and unrecovered based on evidence collected at follow-up with biological samples (urine and hair specimen). All participants were interviewed at two-part intake interviews, extracting demographic information and assessment information using clinical instruments such as DIS, CIDI, SCL-90, all participants received incentives in the intake and follow-up. Other instruments and measures were used for determining perceptions of recovery (Centre for therapeutic Community Research, CTCR Scales(C), as well as self-report measures for determining the patient status after 5 years in both groups, regarding treatment experience and demographic background.

The authors conducted ANOVA to identify background; DATOS treatment experience and attribution of recovery differences between the two groups and the odds ratio for each variable were used as an indicative for discriminators between group predictors. For background variables in 5 years, no differences between groups were found with an exception of legal pressure and treatment readiness, which leads to comment that confounders due sample were controlled. On the other hand due to case-control design, some selection bias may be introduced when classifying participants in each group, but self-report for alcohol use, illicit substances and criminal activities, reinforced with biological measures for abstinence, reduces considerably the 
risk of selection bias due to the design. In relationship with patient treatment experience, significant differences were found between groups in 12-Help variable (which measure the level of attendance in the last year before follow-up) and NA attendance (see odds ratio in Table 2.1). Finally the findings regarding recovery perceptions showed that $\mathrm{R} / \mathrm{S}$ was more likely to be reported as a source of recovery support in comparison with unrecovered patients (see Table 2.1 ). In the context of this study, they assessed $\mathrm{R} / \mathrm{S}$ and $63 \%$ of those in recovery, reported as "very much" the contribution of $\mathrm{R} / \mathrm{S}$ as a source of recovery support, being personal motivation the most common source reported at $83 \%$, and family was reported as much as R/S. We must take into account that the instrument used for score $\mathrm{R} / \mathrm{S}$ was addressing perceptions, therefore, was not specifically designed for spiritual assessment and the internal consistency of this instrument was not reported.

\subsubsection{Longitudinal Design}

Two longitudinal articles were found for the purpose of this review; interestingly both are related with forensic research.

Chen [67], sponsored by the Israeli Anti-Drug Authority performed longitudinal research over 2 year period to compare personal and emotional modifications in voluntary inmates from Israelite prisons (two maximum and one minimum security) who enrolled at two different programs, one including social support (NA meetings) and experiential spiritual program (twelve-step course, $n=43$ ), the other just with social support (NA meetings, $\mathrm{n}=50$ ), no randomization was conducted. Due to the lack of females, setting and the high percentage of Israeli Jewish $(71 \%)$, this sample is less representative than the rest of the studies reviewed at this stage. All participants were fully abstinent during the study, monitored by routine urine tests, with similar criminal backgrounds (substance use related), and long-standing history of substance abuse, no clinical diagnosis or clinical instruments for assessment were reported.

Treatments were described for each group, with balanced hours between groups, the twelve-step course lasted for 6 months, 4 hours per day, whereas NA meetings were held for 1 year of two hours length. The twelve-step course was conduct by two instructors (two veteran recovered inmates), the content of the course was reviewing each step in a comprehensive manner, and in addition participants answered questions in relationship with the step covered. On the other hand NA meetings focused on topic, sobriety birthdays, share experiences and group dynamics. The number of hours of NA meetings held in the group that also attended to the twelve-step course was not specified in the study. A follow-up of 4 intervals (see Table 2.1) were conducted, the third interval (6 months) was only conducted for the group that attended the twelve-step course, measurements in sense of coherence (SOC), depression, anxiety, hostility and meaning of life, were taken (all instruments showed internal consistency and alpha was reported in the article). Chen performed z-test and chi-square for spotting differences in criminal behaviour, and these differences were insignificant, inasmuch as 6 months abstinence prior to the study that was considerably higher for one group ( $87 \%$ vs. $40 \%$ see Table 2.1 ). Due to these salient characteristics between groups for the purpose of the study, the author controlled abstinence statistically when comparisons between groups were analysed.

Repeated measures of MANOVA were conducted for each group with the purpose of analysing the change scores in each interval, previous MANCOVA analysis showed no differences between groups at the first measurement $(\mathrm{F}=0.82$, 4/87df, p-value was not reported).

Those who attended the NA meetings in addition to twelve-step course, showed a significant gradual improvement in SOC and negative emotions between intervals 1 to $3(\mathrm{~F}=7.89,8 / 160 d f, \mathrm{p}<.001)$, the comparisons between the $3^{\text {rd }}$ and $4^{\text {th }}$ interval remained stable with the exception of SOC that kept increasing. The primary changes in anxiety, SOC and hostility occurred between the $1^{\text {st }}$ and $2^{\text {nd }}$ interval, while depression main changes happened between the $2^{\text {nd }}$ and $3^{\text {rd }}$ interval. The primary improvement was in hostility between the $1^{\text {st }}$ and $3^{\text {rd }}$, between the $1^{\text {st }}$ and the $4^{\text {th }}$ all variables showed significant differences $(p<.001)$, the variable meaning of life due to its similarity with SOC (colinearity, $r>$.75) was evaluated in solitude, but the author also found a gradual increase that was significant between the $1^{\text {st }}$ and $3^{\text {rd }}(\mathrm{F}=5.22,1 / 33 d f, \mathrm{p}<.05)$ and $1^{\text {st }}$ and $4^{\text {th }}$ $(\mathrm{F}=16.50,1 / 33 d f, \mathrm{p}<.001)$ intervals. In another way, Group 2 (NA meetings only), measured for $1^{\text {st }}, 3^{\text {rd }}$ and $4^{\text {th }}$ intervals did not show a gradual improvement and only significant changes in hostility and depression were founded between $2^{\text {nd }}$ and $4^{\text {th }}$ measurement. Despite low consistency in Meaning of life by repeated measures in Group 2, instead of using the whole subscale, Chen [67], used only one item from that subscale. Participants in Group 2 showed a significant change and increase over time in this variable (Mann-Witney's $z=2.84, \mathrm{p}<.01$ ). The comparison between groups revealed differences in scores and change over the time differs between groups (see Table 2.1).

Duvall, et al. [68] presented a longitudinal research across 12,18 and 24 months among 500 drug court participants in Kentucky, with a follow-up rate of $92 \%$. Sample participants were mainly men and with white ethnic background (see Table 2.1), some reasons for selection bias can be addressed like the influence of being involved in court procedures, and mainly area limitations in which is regarded as a highly religious location. The participants were enrolled in a Drug Court program (Logan, et al. 2000) with three phases of individual plans in where participants attend to NA/AA meetings weekly, have random drug tests, attend to court, medical appointments, assigned support or counselling, maintain a court-approved employment, arrange payments for court obligations and other duties. For the study measures of this program, progress or outcomes were not taken into consideration for this study. The data collection was through 
interviews held at the four time intervals. Just a single-item measurement was used for the variable Faith worded by "When I am stressed, I usually turn to my faith", compared with other studies of this review that might consider a poor measure of spirituality construct, taken into consideration that there are several instruments for assessing this construct; substance use and criminal behaviour were measured through self-report, using reliable instruments (ASI), authors also measured the perceived addiction severity with another instrument with good internal consistency $(\alpha=.85)$.

In their analysis, the authors performed bivariate correlations, with further intention to create a structural equation model. No significant relationships between faith for each interval/wave and substance use variable outcomes were found. On the other hand significant bivariate relationships were found between 12,18 and 24-month faith measure and perceived addiction severity $(r=.11 ; \mathrm{r}=.16$; $\mathrm{r}=.17, \mathrm{p}<.05$, respectively).

Further analysis was conducted using the four faith follow-up measurements and creating a latent variable of persistence turning into faith across time. For better understanding, latent variables are variables that unable to measure directly but are rather inferred through a model, this measurement model fitted well for the study ( $\mathrm{CFI}=$. 981;RMSEA =. 051, upper limit of $90 \% \mathrm{CI}=.070$ ).

With this latent variable of persistence "turning to faith", authors explore direct relationships of the outcome variables, they develop a structural equation model for exploring the mediation of persistence in turning to faith with the rest of variables and found that participants with higher levels of persistent faith across the time, reported less frequency use of substances at 24 months with a regression coefficient $\beta=-0.75, p=0.05$. At the same time; some demographic characteristics of participants were related latent variable of persistence about turning into faith among participants across the time such as gender $(\beta=.44, p<.001)$ age $(\beta=.47$, $\mathrm{p}<.001)$ and ethnicity $(\beta=-.73, \mathrm{p}<.001)$. Nonetheless, the reader must be aware that Duvall and colleagues (2008) article was appraised as weak by the quality assessment in this review. The observational nature of this study may give a better understanding of the topic itself and provide with more information, like the cross-sectional studies that are also reviewed below, in spite of everything.

\subsubsection{Cross-sectional Studies}

Due the observational nature of this type of design among other characteristics, all the articles from this design were considered as weak, which is something to be taken into account when studying the results.

For instance, samples tend to be big for this type of design; Atkins \& Hawdon [69] performed a national survey in UUEE of mutual-aid support groups for addiction with 822 participants in different recovery groups, spirituality (AA, NA, WFS) and non-spirituality related (SMART \& SOS). The main characteristics of the survey show a high percentage of white ethnicity participants followed by a considerable amount of female gender predominance (see Table 2.2), probably due to the inclusion of support groups like WFS which is a gender oriented support group with spiritual dimensions. Similarly, aimed participants were found in Zemore \& Kaskutas [70] study, in which 200 recovering alcoholics from different spiritual related support groups were surveyed, most of participants were white and $69 \%$ were at least 1 -year sober, the range of sobriety time in this study ranged from 3 days to 50 years, and despite of this range, descriptive statistics of sobriety in this sample (see table 2.2) showed how the majority of participants were considered as recovered individuals.

The next biggest sample of cross sectional designs was in Pardini et al. [71], the salient characteristics of this sample were found in the belonging religious affiliation within participants $(74 \%)$, along with the fact that most of them were residents of treatment homes. On the other hand Brush \& McGee [72] analysed a more specific sample among homeless participants, also predominantly white $(67 \%)$ and catholic $(56 \%)$, the reader may think that homeless are not enough representative, but the majority of professionals working in these settings may recognise the high percentage of homeless people that suffer from addictions, and how this extreme case context might be used as an example for the aim of this study.

Contrary to the rest of the cross-sectional studies, Brush and McGee [72] did not take any measurement for quantifying substance use or treatment attendance, but all participants were homeless in recovery from substance addiction, whereas others measured sobriety, addiction severity and program participation $[69,70]$ or focused in positive mental health outcomes [71].

In relationship with the spirituality related variables measured, three of the four cross-sectional studies examined used instruments designed for the assessment of spirituality with Cronbatch's alpha around .90 or superior, but all using different scales such as DES, SPS and SCSRF. The exception was observed at Atkins and Hawdon [69], who used 15 self-constructed items with religiosity and belief in Higher Power factors.

In regard with findings and statistical analysis, the study examining homeless from Brush and McGee [72], provides the weakest findings in relationship with spirituality, note that this study examined spiritual perspectives, but the analysis conducted in this study was purely descriptive, therefore for the interpretation of the results we should take into consideration that these relationships are not causal. They results describe a high importance of spirituality in their recovery, and an important factor in decision taking across the life-span (see Table 2.2), also homeless participants reported to use meditation/prayer and $75.8 \%$ reported to agree or strongly agree about seeking spiritual guidance in daily life experiences $(M=4.91, \mathrm{SD}=1.31)$, the author explored each item from the scale in a descriptive manner to provide with conclusions about how these homeless used the spirituality construct in the hospice during 
their recovery.

On the contrary, Zemore and Kaskutas [70] performed a robust structural equation modelling in which spirituality was divided into theism and self-transcendence, one related with the spiritual experience daily, the other related with connection with the universe, both were treated in the model as latent variables while controlling other confounding variables of the study. In their findings, longer sobriety was significantly associated with higher levels of these two factors (see Table 2.2), at the same time performing good actions towards community, such as volunteering, were also related with longer sobriety. AA participation variables were also included in the model and showed an association with the participants' length of sobriety $(\beta=-.67, p<.001)$. An examination of residual covariances shows relationship between spirituality and helping variables (recovery, community and life), as well as an association between AA participation variables, theism and recovery helping, a variable that can be interpreted as a self-report measurement of the importance of helping others in their recovery, like sponsorship, or sharing moments during the meetings.

Pardini and colleagues [71], conducted a hierarchical multiple regression analysis, they differentiated between spirituality and religious faith and found that spirituality tends to predict better optimism, social life and less anxiety (see regression coefficients at Table 2.2) whereas religious faith predicts just more resilience to stress $(\beta=0.21, \mathrm{p}<0.01)$.

While most of studies reviewed shown positive findings towards our hypothesis, the national survey conducted by Atkins and Hawdon [69] in their OLS regression where they explored the factors influencing recovery, religiosity or belief in a Higher Power, were found not significant (see Table 2.2). On the other hand the regression calculated for predicting program participation in mutual-aid support group, showed religiosity as a significant predictor for program participation, but it is recommended to take into account that in the survey there were more spiritual-related support groups than secular groups, which may be a source of bias when they interpreted these results.

Overall, most of the studies search and explore non-causal relationships between spiritual variables and substance use outcomes, but once more, the diversity of instruments, settings, participants, programs and analyses, forces this review to carefully interpret these results, trying to provide understanding to prevent the reader from reaching fast and biased conclusion of these results. 
Table 2.1. Summary of the findings for Observational studies (Case-Control Studies, Longitudinal Studies \& Cohort Studies).

\begin{tabular}{|c|c|c|c|c|c|c|c|}
\hline \multirow[b]{2}{*}{ Rating/Design } & \multirow[b]{2}{*}{ Study/Country } & \multirow[b]{2}{*}{ Sample Characteristics } & \multirow[b]{2}{*}{ Follow-up } & \multirow[b]{2}{*}{ Intervention } & Outcomes & & \multirow[b]{2}{*}{ Findings } \\
\hline & & & & & $\begin{array}{l}\text { Substance } \\
\text { use/relapse }\end{array}$ & $\begin{array}{c}\text { Spiritual } \\
\text { Measures }\end{array}$ & \\
\hline$++/ \mathrm{CCS}$ & $\begin{array}{l}\text { Sterling et al. } \\
\text { (2007) } \\
\text { USA }\end{array}$ & $\begin{array}{c}\mathrm{n}=278 ; \\
\mathrm{n}=36, \text { who reported relapse at } 3 \\
\text { months follow-up vs. } \mathrm{n}=36 \\
\text { non-relapsed } \\
\text { Age }=18+ \\
94.4 \% \text { Caucasian } 61 \% \text { male; } \\
\mathrm{M}=22.90 \text { years of history } \\
\text { drinking. } \\
89.4 \% \text { Christians, } 31.3 \% \text { regular } \\
\text { service attendance }\end{array}$ & $\begin{array}{l}\text { Intake, } \\
\text { end-of-treatment } \\
\text { and } 3 \text { month } \\
\text { follow-up }\end{array}$ & $\begin{array}{l}\text { Inpatient } \\
\text { alcohol } \\
\text { treatment }\end{array}$ & $\begin{array}{c}\text { Relapse/No } \\
\text { relapse }\end{array}$ & $\begin{array}{c}\text { DSES, } \\
\text { BMMRS, } \\
\text { RSCOPE, SEI, } \\
\text { INSPIRIT. }\end{array}$ & $\begin{array}{c}\text { In-treatment spiritual growth: } \\
\text { Two-way repeated measures analysis: } \\
\text { BMMRS= revealed that } 83 \% \text { reported spiritual component to } \\
\text { treatment was considerably or extreme important; } \\
\text { Paired t-test analysis: } \\
\text { RSCOPE }=\uparrow \text { Spiritual levels no matter if was relapse in } \\
\text { post-treatment follow-up (Ms }=19.43 \pm 4.65 \text { and } 21.25 ; \\
\mathrm{t}(71)=4.51, \mathrm{p}<.001 \text { ) same for the rest spirituality measures } \\
\text { Maintenance of effects: } \\
\text { 3x2 ANOVA repeated measures: } \\
\text { Significant main effect of time in (DSES, SBS, SEI and } \\
\text { INSPIRIT). Simple effects test for end-of-treatment and } \\
\text { follow up, only significant differences in INSPIRIT } \\
\text { Spiritual growth and abstinence: } \\
\text { 2x2 ANOVA (relapse } / \text { non-relapse and time): } \\
\text { Interactions effects of DSES }(\mathrm{p}=.08 \text { ) and SEI }(\mathrm{p}=0.3 \text { ) were } \\
\text { found, at 3-month follow-up and significant decrease of SEI to } \\
\text { those who relapse }(\mathrm{t}(31)=3.01, \mathrm{p}<.01) \text {. }\end{array}$ \\
\hline$++/ \mathrm{CCS}$ & $\begin{array}{l}\text { Flynn, et al. } \\
\text { (2003) } \\
\text { USA }\end{array}$ & $\begin{array}{l}\mathrm{N}=708 \text {; national sample from } \\
\text { DATOS } \\
\text { Recovered }(\mathrm{n}=235) ; \\
\text { Unrecovered }(\mathrm{n}=473) \\
\text { Males }(64 \%) \text {; African American } \\
\text { (56\%); Differences on legal } \\
\text { pressure }(\mathrm{p}<0.01) \text { and motivation } \\
\text { at admission. }\end{array}$ & 5 years & $\begin{array}{l}\text { LTR, STI, } \\
\text { ODF, OMT }\end{array}$ & $\begin{array}{c}\text { Recovery vs. } \\
\text { Unrecovered } \\
\text { Negative urine and } \\
\text { hair, self-report of } \\
\text { "no use", less than } \\
\text { daily alcohol use, } \\
\text { no report of illegal } \\
\text { activity. }\end{array}$ & $\begin{array}{l}\text { TS Help (AA, } \\
\text { NA) \& } \\
\text { S/R (source of } \\
\text { recovery } \\
\text { support factor) }\end{array}$ & $\begin{array}{c}\text { ANOVA: } \\
\text { Additional12-Step help was more likely between recovered } \\
(55 \%) \text { and unrecovered }(44 \%) ; \\
(\mathrm{OR}=1.35[95 \% \mathrm{CI}=0.99-1.85]) \mathrm{p}<0.1 \\
\text { NA attendance was more likely in recovered }(38 \%) \text { than } \\
\text { unrecovered }(27 \%) ;(\mathrm{OR}=1.63[95 \% \mathrm{CI}: 1.17-2.27]), \mathrm{p}<0.01 \\
\text { Religion/spirituality was more likely to be reported as a source } \\
\text { of recovery support in recovered }(63 \%) \text { in comparison with } \\
\text { unrecovered }(44 \%) \text {. (OR=2.12[95\%CI: } 1.54-2.93]), \mathrm{p}<0.0001\end{array}$ \\
\hline$+/ \mathrm{CAS}$ & $\begin{array}{l}\text { Miller et al. } \\
(2008) \\
\text { Study } 2 . \\
\text { USA }\end{array}$ & $\begin{array}{c}\mathrm{N}=80 ; \mathrm{n}=40 \mathrm{TAU} ; \\
\mathrm{n}=40(\mathrm{TAU}+\mathrm{SG}) \\
(52.5 \% \text { male) } \\
\text { Enrolled Age = 18+; } \\
\text { Criteria for DSM-IV substance } \\
\text { Dependence; } \\
\text { Hispanic (56\%); non-Hispanic } \\
(28 \%) ; \text { Native American (6\%). } \\
\text { Confounder controlled and } \\
\text { measured at baseline (Age, } \\
\text { Gender, Ethnicity, substance } \\
\text { abuse and } 19 \text { psycho-spiritual } \\
\text { variables); Except family income } \\
\text { (TAU higher). }\end{array}$ & $\begin{array}{l}3,6 \text { months } \\
\text { Follow-up }\end{array}$ & $\begin{array}{c}\text { Polydrug } \\
\text { detoxificatio } \\
\mathrm{n}-\mathrm{SG} \text { or } \\
\text { SG+TAU }\end{array}$ & $\begin{array}{c}\text { Substance use } \\
\text { outcomes (PDA) } \\
\text { Anxiety = STAI; } \\
\text { Depression= BDI; } \\
\text { Self-esteem=[SEI] } \\
\text { inventory }\end{array}$ & $\begin{array}{l}\text { BMMR with } \\
\text { special interest } \\
\text { in= Daily } \\
\text { Spiritual } \\
\text { experiences, } \\
\text { Meaning in life, } \\
\text { Private religious } \\
\text { practices. }\end{array}$ & $\begin{array}{c}\text { Group } \mathrm{x} \text { Time repeated measures ANOVA } \\
\text { SG and TAU } \downarrow \text { substance use over the time }(\mathrm{p}<.001) ; \\
\mathrm{SG}=\mathrm{TAU} \\
\chi^{2} \text { test for PDA at } 3 \text { and } 6 \text { months follow up: } \\
\uparrow \text { for } \mathrm{SG} \text { but not significant }(\mathrm{p}>.05) \text { in comparison with TAU; } \\
\uparrow \text { Daily Spiritual experiences }(\mathrm{F}(1,53=4.146 \mathrm{p}=.047) \text { than } \\
\text { TAU at } 3 \text { month; } \uparrow \text { Daily Spiritual experiences ( } \mathrm{F}(1, \\
47=4.924 \mathrm{p}=.04) \text { than TAU at } 6 \text { month; But not mediate the } \\
\text { relationship between } \mathrm{SG} \text { and PDA. }\end{array}$ \\
\hline
\end{tabular}




\begin{tabular}{|c|c|c|c|c|c|c|c|}
\hline$++/ \mathrm{LS}$ & $\begin{array}{c}\text { Chen, (2006) } \\
\text { Israel }\end{array}$ & $\begin{array}{c}\mathrm{N}=93 \text {; inmates. } \\
\text { Group } 1(\mathrm{n}=43) \text { : } \mathrm{NA}+12 \text {-step } \\
\text { program; abstinent }>6 \text { months } \\
(87 \%) \\
\text { Group } 2(\mathrm{n}=50) \text { : NA abstinent }> \\
6 \text { months }(40 \%) \\
\text { Males }(100 \%) \\
\text { Israeli Jewish }(71 \%) \\
\text { Mean age }=32\end{array}$ & $\begin{array}{l}\text { Prior, } 3 \text { months, } \\
\text { 6months, } 12 \\
\text { months (end of } \\
\text { program) }\end{array}$ & $\begin{array}{l}\text { NA meetings } \\
\text { or NA } \\
\text { meetings }+ \\
12 \text {-step } \\
\text { program }\end{array}$ & $\begin{array}{l}\text { SOC; State of } \\
\text { anxiety; } \\
\text { Depression; } \\
\text { Hostility; Meaning } \\
\text { in life. }\end{array}$ & None & $\begin{array}{c}\text { MANOVA Controlling length for drug abstinence }\left(1^{\text {st }} \text { to } 4^{\text {th }}\right. \\
\text { Intervals) } \\
\text { Comparison: } \\
\uparrow \text { SOC \& Meaning of life in Group } 1 \\
\downarrow \text { Negative emotions in Group 1. } \\
\text { Significant TimeXgroup interactions: } \\
\text { SOC }(\mathrm{F}=4.14,1 / 78 \mathrm{df}, \mathrm{p}<0.05) ; \\
\text { Anxiety }(\mathrm{F}=5.52,1 / 78 \mathrm{df}, \mathrm{p}<0.05) ; \\
\text { Depression }(\mathrm{F}=4.32,1 / 78 \mathrm{df}, \mathrm{p}<0.05) ; \\
\text { Hostility }(\mathrm{F}=5.08,1 / 78 \mathrm{df}, \mathrm{p}<0.05) ;\end{array}$ \\
\hline$+/$ LS & $\begin{array}{c}\text { Duvall, et al. } \\
\text { (2008) } \\
\text { USA }\end{array}$ & $\begin{array}{c}\mathrm{n}=500 \text {; Drug Court Clients; } \\
\text { Self-admitted drug problem; } \\
\text { criteria for substance abuse } \\
\text { (ASI); } \\
\text { Male }(65.4 \%) \\
\text { White }(61.8 \%)\end{array}$ & $12,18,24$ months & $\begin{array}{l}\text { Drug Court } \\
\text { program } \\
\text { (With } \\
\text { mandatory } \\
\text { AA/NA } \\
\text { attendance) }\end{array}$ & $\begin{array}{c}\text { Substance Use; } \\
\text { Criminal } \\
\text { behaviour; ASI }\end{array}$ & $\begin{array}{l}\text { Faith: Single } \\
\text { item measure }\end{array}$ & $\begin{array}{c}\text { Structural model: } \\
\text { Good fit }(\mathrm{CFI}=0.937 ; \mathrm{RMSEA}=0.057 \text {, upper limit } \\
90 \% \mathrm{CI}=0.072) \\
\text { substances } \\
(\beta=-0.75, \mathrm{p}=0.05) \\
\text { levels or persistent faith across time reported } \downarrow \text { use of } \\
\text { levels or persistent faith across time reported } \downarrow \text { Criminal } \\
\text { behaviour } \\
(\beta=-0.82, p=0.05)\end{array}$ \\
\hline
\end{tabular}

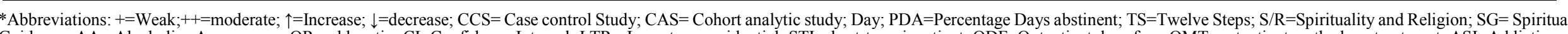

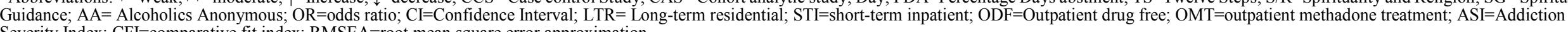
Severity Index; $\mathrm{CFI}=$ comparative fit index; RMSEA $=$ root mean square error approximation. 
Table 2.2. Summary of the findings for Observational studies (Cross-Sectional)

\begin{tabular}{|c|c|c|c|c|}
\hline \multirow{2}{*}{ Study/Country } & \multirow{2}{*}{ Sample Characteristics } & Variables & & \multirow{2}{*}{ Findings } \\
\hline & & Substance use/relapse & Spiritual Measures & \\
\hline $\begin{array}{l}\text { Zemore \& Kaskutas, } \\
\text { (2004) } \\
\text { USA }\end{array}$ & $\begin{array}{c}\mathrm{n}=200 ; \text { Recovering alcoholics } \\
\text { from AA, WS, LR, OC. } \\
\text { White }(83 \%) ; \\
\text { Female }(40 \%) \\
\text { Age } \\
\text { (21-82; Mean }[\mathrm{SD}]=47[12.5]) \\
\text { 1-year sober }(69 \%): \\
\text { Sobriety ranged (3days }-50 \text { years; } \\
\text { Mean }[\mathrm{SD}]=6.8[8.3])\end{array}$ & $\begin{array}{l}\text { Addiction severity; Length of } \\
\text { sobriety; } \\
\text { Helping (Recovery, Life, } \\
\text { Community) }\end{array}$ & $\begin{array}{c}\text { AA participation= } \\
\text { AA involvement/AA } \\
\text { Achievement; } \\
\text { Spirituality (DSE) }= \\
\text { Theism/Self-transcendence. }\end{array}$ & $\begin{array}{c}\text { Structural Model: } \\
\text { Good fit } \\
\begin{array}{c}\left.\chi^{2}=384,196 \mathrm{df}, \mathrm{p}<0.001, \mathrm{CFI}=0.92, \mathrm{TLI}=0.90, \mathrm{RMSEA}=0.08[0.068-0.092]\right) \\
\text { Longer sobriety significantly associated }= \\
\uparrow \text { Community helping; }(\beta=0.23, \mathrm{p}<0.01) \\
\uparrow \text { Self-Transcendence; }(\beta=0.19, \mathrm{p}<0.01) \\
\uparrow \text { Theism; }(\beta=0.16, \mathrm{p}=0.05) \\
\downarrow \text { Recovery helping; }(\beta=-0.21, \mathrm{p}<0.01) \\
\text { Residual covariance association between AA Achievement with Theism } \\
(0.21, \mathrm{p}<0.01) \text { and Recovery Helping }(0.24, \mathrm{p}<0.001) .\end{array}\end{array}$ \\
\hline $\begin{array}{l}\text { Atkins \& Hawdon, } \\
\text { (2007) } \\
\text { USA }\end{array}$ & $\begin{array}{c}\mathrm{N}=822 \text {; National survey for people } \\
\text { in recovery for substance abuse in } \\
\text { mutual aid support groups. } \\
\text { 12-Steps }(\mathrm{n}=161) ; \\
\text { SOS }(\mathrm{n}=104) ; \\
\text { SMART }(\mathrm{n}=321) ; \\
\text { WFS }(\mathrm{n}=236) ; \\
\text { Other }(\mathrm{n}=102) ; \\
\text { Age }(18-82, \text { Mean }=47) ; \\
\text { Females }(58.8 \%) ; \\
\text { White }(90.3 \%) ;\end{array}$ & Sobriety, Program participation & Religiosity; Higher power- & $\begin{array}{l}\text { OLT regression for prediction of sobriety: } \\
\text { Religiosity }(\beta=0.104, p>0.01) \text { and Higher Power }(\beta=0.026, p>0.01) \text { not } \\
\text { significant. } \\
\text { Regression for prediction of program participation: } \\
\text { Religiosity was significant }(\beta=2.94, p<0.001)\end{array}$ \\
\hline $\begin{array}{c}\text { Pardini, et al. (2000) } \\
\text { USA }\end{array}$ & $\begin{array}{c}\mathrm{n}=236 \\
\text { Males }(55.5 \%) ; \\
\text { Age Mean [SD]=37.10[11.64] } \\
\text { White }(61 \%) ; \\
\text { Religious affiliation }(74 \%) ; \\
\text { Residents of sober living and } \\
\text { treatment homes }(81 \%)\end{array}$ & $\begin{array}{c}\text { Life orientation (LOT); Social } \\
\text { provisions (SPS) ; Trait anxiety } \\
\text { (TMA);Hardiness to stress (HS); } \\
\text { Social desirability (MCSD). }\end{array}$ & $\begin{array}{l}\text { Self-Reported Spirituality; } \\
\text { Religious Faith (SCSRF); } \\
\text { Religious importance }\end{array}$ & $\begin{array}{c}\text { Hierarchical Multiple Regression: } \\
\text { Spirituality predicts: } \\
\uparrow \text { Optimism }(\beta=0.31, \mathrm{p}<0.01) \\
\uparrow \text { Social Provisions }(\beta=0.33, \mathrm{p}<0.01) \\
\downarrow \text { Trait anxiety }(\beta=-022, \mathrm{p}<0.01) \\
\text { Religious faith predicts: } \\
\uparrow \text { Hardiness to stress }(\beta=0.21, \mathrm{p}<0.01) .\end{array}$ \\
\hline $\begin{array}{c}\text { Brush \& McGee, (2000) } \\
\text { USA }\end{array}$ & $\begin{array}{c}\mathrm{n}=100 ; \\
\text { Homeless; } \\
\text { Males; } \\
\text { Age Mean[SD] }=40.5[9.8]) ; \\
\text { White }(67 \%) ; \\
\text { Catholic }(56 \%) ; \\
\end{array}$ & None & SPS* & $\begin{array}{c}\text { Descriptive analysis: } \\
\text { Spirituality important aspect for homeless men in recovery (82\%) } \\
\text { Mean[SD] }=5.29[1.13] \text {; } \\
\text { Spiritual views influence decisions (76\%) Mean }[\mathrm{SD}]=5.05[1.29] \\
\text { Individuals weekly engaged in spiritual practices Mean }[\mathrm{SD}]=5.31[1.5]\end{array}$ \\
\hline
\end{tabular}

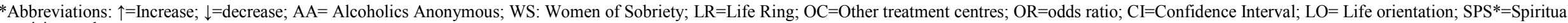
provision scale. 


\section{Discussion}

The main findings in the experimental studies reviewed, showed that there is not enough evidence in the current scientific literature to fully accept our initial hypothesis; five experiments were reviewed and only a few were robust on the quality assessment.

Therefore, it seems that the findings for the reviewed studies, broadly tend to discard the main hypothesis of this systematic review, but if we examine carefully the characteristics of each study, in all of them the outcome measures such as PDA, DDD, sobriety \& relapses showed a reduced rate. On the other hand, spirituality-related variables explained or predicted a considerable amount of the model for recovery, therefore, a relationship between addiction recovery and spirituality were found in the reviewed studies, and lower prevalence on substance abuse outcomes that answer our second research question.

It is true that no differences in efficacy between spiritual-treatments were found, compared with regular secular treatments in any of the studies, or at least the effect of the treatment was not directly observed, but there were significant differences and better outcomes for substance use problems in most of the papers that included spirituality-related programs.

For not biasing our conclusion, we need to take into consideration that many of the interventions reviewed were related with twelve-step programs; also some of the studies did not examine spirituality in the same way as a construct. These programs due to their organic gestation within the community, are difficult to measure compared to other interventions, the nature of the contexts that they apply, anonymity, co-occurrence with additional treatments, and other specific characteristics, only allow self-report measures to determine the effect of twelve-step interventions and spirituality related-interventions.

Neff and MacMaster [73] came up with a suggestion after carrying out a twelve-step intervention analysis, that social support and peer influence processes can be enhanced through creating programs that enhance a sense of spirituality, meaning, forgiveness and spiritual connectedness. Such an intervention could motivate further engagements into treatment activities and objectives (i.e., enhancing social integration). These authors put a special emphasis on the "radical but not necessarily immediate, change in the self" in relation to contact with "other", which includes a higher power and/or its social environment as they reflect on existential characteristics of spiritual transformation. They further suggest that an association exists between a person's initial level of spirituality and their social engagement, self-efficacy, and positive coping with substance use stressors, for example "craving".

Maybe it is difficult to explore the effects of spirituality due to the heterogeneity of design and articles reviewed, and the interpretations should be taken carefully due to this fact. There is not enough evidence to provide a truly homogeneous systematic analysis of the available articles, at least not at this point in the state of the art. The outcomes are similar but different in each case; the method for measuring spirituality variables and the design and treatment types, also varied broadly.

Miller et al. [59] in their controlled trial were struggling to find better outcomes for the Spiritual guidance program (a treatment strictly spiritual), whereas we must note that the study was rated as weak in the quality assessment. It is also noted that the adherence to this treatment was very low, something that could explain the main findings. The longitudinal study from Chen [67] showed how the group that was allocated with spirituality-related treatment $(\mathrm{NA}+12$ step) showed better psychological outcomes than the one that did not include spiritual measures.

From the case-control studies analysed $[61,65,66]$, those who recovered and not recovered after different treatments for substance abuse, and already recovered individuals reported more spirituality as a source of recovery than non-recovered. This increase in spirituality was explained by spiritual practices, involvement in spirituality programmes, or increases in spiritual variables. Findings show that proactive and experiential dimensions of spirituality, such as meditation, instead of cognitive dimensions of spirituality, contributed to recovery and less drinking within the first 6 months [74].

All the models for recovery, examined from observational and experimental studies, placed spirituality as a predictor variable for better substance use outcomes, and all participants of experimental studies examined were involved in twelve-step programmes or engaged with spirituality related behaviours to some extent. Piderman and colleagues [75] concluded in their study about spirituality during treatment in alcoholic population, that it is fundamental for improving the initial stage of recovery, and spiritual well-being, religious practices, and positive religious coping may help to this change towards recovery.

Spirituality might be a domain that increases within longer periods of time; maybe just one year of follow-up is not enough to foster spirituality during the recovery, as reported by qualitative research [23]. Other investigators found that changes in individuals' purpose in life or sense of meaning, leads to increases in likelihood of alcoholic abstinence [7678] and changes in these dimensions may as well take long periods.

Spirituality, considered as multi-dimensional, was measured by most of the studies selected. The poorest multi-dimensional approach in all experimental studies reviewed was Kelly et al. [60], but the challenge of multi-dimensionality is also reflected in determining to which extent the treatment helps to foster this domain. Furthermore, this relationship is difficult to explain with clinical trials, this fact is supported by the results of the Cross-Sectional studies reviewed, which revealed how different factors of spirituality are related with positive outcomes in recovery, factors such as self-transcendence, 
spiritual practices (such as pray/meditation), forgiveness, or altruism, that can all be part of spirituality-related treatments and seems to have a relationship with recovery.

\subsection{Implications for Future Research}

During this systematic review, some limitations were encountered and implications for better development of future research. Conceptualising spirituality as a multi-dimensional construct and using the working definition provided in the review by Cook [6] is recommended. More RCT and Clinical trials, which include spiritual oriented treatment, are needed in the field in order to determine if spirituality related treatments are more effective in treatment of addictions and to achieve recovery.

There is a wide range of different spiritual measurements, but those provided by the Fetzer institute seem to be the more reliable for assessing the multi-dimensionality as addressed in Sterling et al. [65] study, but maybe a higher consensus about the instruments that should be used is recommended [80]. For exploring the effectiveness of twelve-step programmes or spirituality-related treatments, more randomized controlled trials are needed, there is not enough evidence to support the effectiveness and to compare them with other treatments such as CBT or Contingency management, or to extract the most important spiritual elements of achievement in such programs, in order to develop new interventions that can be formally applied in care settings.

\subsection{Implications for Clinical Practice}

There is a lack of information about how the treatments include the spirituality, even more; there is not enough evidence in quantity of studies about treatments that include the spiritual domain in their practice. Some studies explored spiritual practices, whereas other focused into examining latent variables or broad and more difficult to measure variables such as connectedness from the others, also there is some controversy between twelve-step programmes and AA meetings and to which extent these really cover this construct of inquiry.

It is dubious to conclude if it is appropriate to recommend clinicians about including the spirituality domain into their clinical practice when they are dealing with substance misuse; nevertheless it seems that there is still a broad field of promising research to clarify the extent and the necessity of this inclusion. Even if no conclusive data was found, the encouragement to approach the spirituality domain if the person seems to require or requests it, still seems to be adequate for clinical practice to try to identify patients' spiritual needs and to encourage clinicians about having a mature and self-reflective sense of personal spirituality [79, 81-83].

Transcultural assessments to approach addictions and ethnicity may play an important role for the therapy, Duvall et al. [68] found significant differences regarding ethnicity, also several studies reviewed show high percentage of predominant ethnicity (White), as well as population that recognise their religious background rather than non-religious population. Assessing the spirituality and cultural background and matching client characteristics to treatments is fundamental for successful projects like ECHO [72] or MATCH [61].

The empowerment person-centred approach for recovery includes this domain for community intervention in many settings (social work, nursing, clinical psychology) and countries such as the UK or Australia. Assuming that spiritual change is not related with substance misuse, rather than taking into account the lack of research in this topic, is something that clinicians might judge by themselves.

\subsection{Strengths and Limitations}

These review analysed studies, which include spirituality as a measured construct by different dimensions. Nowadays, other interventions based in compassionate mind and training in spiritual practices, can be considered spiritual [84]. On the other hand this review only covered articles, which named interventions as entire spirituality-related programs. A broad spiritual perspective within treatment modality may provide better understanding of this key element from the construct, as was suggested by Peter Gilbert in his handbook for spirituality and mental health [84].

The lack of studies that explore spirituality was evidenced in the whole review; also the diverse path for exploring the construct was also a limitation that biases any conclusions for this review. On the other hand, only quantitative studies were examined, some may argue that such a broad construct is impossible to measure through numerical data, far from the truth since all the articles used robust multi-dimensional tools for measuring this construct. And with previous qualitative researches supporting these instruments, it seems adequate to keep improving such tools rather than keep the construct broad and undefined.

There was not enough data to conduct any meta-analytical analysis, and also only one researcher was in charge of the whole systematic research, which needs to be considered as a huge limitation for quality assessment or systematic selection of studies.

\section{Conclusions}

From this systematic review, it is clear to extract that spirituality is a construct under development in the scientific field, that might have a huge impact in the near future for understanding dynamics, belief systems and spiritual behaviours related with better health outcomes [11], and consequently allow to implement better ways for the inclusion of this construct.

It is clear that addictions disorders are a 
bio-psycho-social problem, and after this review, we may attempt to include at the end of the disease model, the spiritual field to conceptualise the whole problem (bio-psycho-social+"spiritual"). But also some future research regarding this model may be useful to take into consideration at clinical practice.

The recently published DSM-V, attempted to clarify addiction rather than dependence, and also promising research of brain circuitry [82] involved in addiction dynamics, may help in the near future to understand better why spiritual beliefs and behaviours are prone to better outcomes when reducing addictive patterns and foster recovery.

Recently, the eminent Thomas Insel stated that brain circuitry will be essential for understanding mental health in the future [86], to explore the neurological correlates of spiritual behaviours and beliefs that help in therapy in order to reduce addictive behaviours may fill the gap of why this individualistic essential construct has such a good reputation within recovered individuals.

\section{Acknowledgements}

We are also grateful to all the ground breaking scholars researching in spirituality and who kindly provided with their texts and suggestions about the review.

\section{REFERENCES}

[1] Jung, C. J. (1961/1975) Letter to William G. Wilson, 30 January, 1961, in: ADLER, G. (Ed.) Letters of Carl G. Jung, vol. 2. London: Routledge \& Kegan Paul. 623 - 625.

[2] Koenig, H., McCullough, M., \& Larson, D. (Eds.). (2001). Handbook of Religion and Health. New York: Oxford University Press.

[3] Heinz, A., Disney, E., Epstein, D., Glezen, L., Clark, P., Preston, L. (2010). A focus-group study on spirituality and substance-user treatment. Substance Use \& Misuse, 45(1-2), 134-153.

[4] Swinton, J., (2001). Spirituality and Mental Health Care: Rediscovering a forgotten dimension. London: Jessica Kingsley. Publishers.

[5] Swinton, J., \& S. Pattison, (2001). Spirituality. Come all ye faithful. Health Serv.J.111:5786, 24-25.

[6] Cook, C. (2004). Addiction and spirituality. Addiction, 99, $539-551$

[7] Decker, L.R. (1993). The role of trauma in spiritual development. Journal of humanistic Psychology, 33(4), 33-46.

[8] Johnsen, E. (1993). The role of spirituality in recovery from Chemical dependancy. Journal of addictions \& Offender Counseling. 13(2), 58-61.
[9] Snow, M. G., Prochaska, J. O., \& Rossi, J. S. (1994). Processes of change in Alcoholics Anonymous: Maintenance factors in long-term sobriety. Journal of Studies on alcohol, 55(3), 362-371.

[10] Fetzer Institute \& National Institute on Aging Working Group. (1999). Multidimensional Measurement of Religiousness Spirituality for Use in Health Research. Kalamazoo: Fetzer Institute.

[11] Underwood, L. G. (2011). The Daily Spiritual Experience Scale: Overview and Results. Religions, 2, 29-50.

[12] Vaillant, G. E. (1995). The natural history of alcoholism revisited. Cambridge, MA: Harvard University Press.

[13] Drake R., McHugo G., Xie H., Fox M., Packard J., Helmstetter B. (2006) Ten-year recovery outcomes for clients with co-occurring schizophrenia and substance use disorders. Schizophrenia Bulletin, 32 (2), 467-473.

[14] Galanter, M. (2007). Spirituality and recovery in 12-step programs: An empirical model. J Subst Abuse Treat. 33, 265272.

[15] Kurtz, E. (1987). Not God: A history of Alcoholics Anonymous. Center City, MN: Hazelden.

[16] Sparks, T. (1987). Transpersonal treatment of addictions: radical return to roots. Revision, 10(2), 49-65.

[17] Small, J. (1987). Spiritual emergence and addiction: A transpersonal approach to alcoholism and drug abuse counselling. Revision, 10(2), 23-36.

[18] Warfield, R. D. \& Goldstein, M. B. (1996). Spirituality: The key to recovery from alcoholism. Counselling Values, 40, 196-205.

[19] Whitfield, C. L. (1984a). Stress management and spirituality during recovery: A transpersonal approach. Part 1: Becoming. Alcoholism Treatment Quarterly, 1(1), 3-54.

[20] Whitfield, C. L. (1984b). Stress management and spirituality during recovery: A transpersonal approach. Part 2: Being. Alcoholism Treatment Quarterly, 1(2), 1-50.

[21] Whitfield, C. L. (1984c). Stress management and spirituality during recovery: A transpersonal approach. Part 3: Transforming. Alcoholism Treatment Quarterly, 1(4), 1-54.

[22] Morjaria, A., Orford, J. (2002). The role of religion and spirituality in recovery from drink problems: A qualitative study of Alcoholics Anonymous members and South Asian Men. Addiction Research \& Theory, 10(3). 225-256.

[23] Miller, M. A. (1995) Spirituality, art therapy, and the chemically dependent person. In: Kus, R. J., ed. Spirituality and Chemical Dependency, 135-144. New York: Haworth Press.

[24] Alcoholics Anonymous World Services. (1975). Alcoholics Anonymous ( $3^{\text {rd }}$ ed.). New York: Author.

[25] Bristow-Braitman, A. (1995). Addiction recovery: 12-Step programs and cognitive behavioural psychology. Journal of Counselling \& Development. 73(4), 414-418.

[26] Fiorentine. R. (1999). After drug treatment: are 12-step programs effective in maintaining abstinence?. American Journal of Drug and Alcohol Abuse, 25, 93-116. 
[27] Fiorentine, R., Hillhouse, M. P. (2000) Drug treatment and 12-step program participation: The additive effects of integrated recovery activities. Journal of Substance Abuse Treatment, 18(1), 65-74.

[28] Weiss, R. D., Griffin, M.L., Najavits, L.M., Hufford, C., Kogan, J., Thompson, H.J., et al. (1996). Self-help activities in cocaine dependent patients entering treatment: Results from the NIDA collaborative cocaine treatment study. Drug and Alcohol Dependence; 43(1-2), 79-86.

[29] Bewley, A.R. (1993). Addiction and meta-recovery: Wellness beyond the limits of Alcoholics Anonymous. Alcoholism Treatment Quarterly, 10(1), 1-22.

[30] Bewley, A.R. (1995). Wellness beyond AA: Testing the theory of meta-recovery. Alcoholism Treatment Quarterly, 13(1), $1-15$.

[31] Chapman. R.J. (1996). Spirituality in the treatment of alcoholism: A worldview approach. Counselling \& Values. 41(1). 39-50.

[32] McCulloch, A. (2006). Understanding mental health and mental illness. In C. Jackson, C. \& K. Hill. (Eds). Mental Health Today: A handbook. Brighton: Pavilion/Mental Health Foundation.

[33] Yalom, I. D. (1980). Existential Psychotherapy. New York: Basic Books

[34] Kurtz, E. \& Ketcham, K. (1992). The Spirituality of Imperfection: Storytelling and the Journey to Wholeness. New York: Bantam Books

[35] Frankl, V. (1972). The Doctor and the soul, (2nd ed.). New York: Alfred Knopf.

[36] Frankl, V. (1997). Man's search for ultimate meaning. New York: Plenum

[37] Wolf, Y., Katz. S., \& Nachson, I. (1995). Meaning of life as perceived by drug-abusing people. International Journal of Offender Therapy and Comparative Criminology, 39, 121-137.

[38] Avants, S.K., Warburton, L.A., \& Margolin, A. (2001). Spiritual and religious support in recovery from addiction among HIV-positive injection drug users. Journal of Psychoactive Drugs, 33(1), 39-45.

[39] McMillen, C., Howard, M.O., Nower, L., \& Chung, S. (2001). Positive by-products of the struggle with chemical dependency. Journal of Substance Abuse Treatment, 20, 69-79.

[40] Arnold, R. M., Avants, S. K., Margolin, A., \& Marcotte, D. (2002). Patient attitudes concerning the inclusion of spirituality into addiction treatment. Journal of Substance Abuse Treatment, 23, 319-326.

[41] Dermatis, H., Guschwan, M. T., Galanter, M., Bunt, G. (2004) Orientation toward spirituality and self-help approaches in the therapeutic community. Journal of Addictive Diseases, 23(1), $39-54$.

[42] Kendler, K.S., Xiao-Qing, L., Gardner, C.O., Larson, D., \& Prescott, C.A. (2003). Dimensions of religiosity and their relationship to lifetime psychiatric and substance use disorders. American Journal of Psychiatry, 160, 496-503.

[43] Jarusiewicz, B. (2000). Spirituality and addiction:
Relationship to recovery and relapse. Alcoholism Treatment Quarterly, 18(4), 99-109.

[44] Mathew, R.J., Georgi, J., Wilson, W.H., Mathew, V.G.(1996). A retrospective study of the concept of spirituality as understood by recovering individuals. Journal of Substance Abuse Treatment, (1), 67-73.

[45] Robinson, E.A.R., Brower, K.J., \& Kurtz, E. (2003). Life-changing experiences, spirtuality and religiousness of persons entering treatment for alcohol problems. Alcoholism Treatment Quarterly, 21, 3-16.

[46] Marlatt. G. A. \& Marques. ]. K. (1977). Meditation. self-control and alcohol use. In R. B., Stuart (Ed.). Behavioral self-management: Strategies, techniques, and outcomes, (17-153). New York: Brunner/Mazel.

[47] Taub, E., Steiner, S. S., Smith, R. B., Weingarten, E., Walton, K. G. (1994). Effectiveness of broad spectrum approaches to relapse prevention in severe alcoholism: A long-term, randomized controlled trial of transcendental meditation, EMG biofeedback and electronic neurotherapy. Alcoholism Treatment Quarterly, 11, 187-220.

[48] Sullivan, W. P. (1993). It helps me to be a whole person: The role of spirituality among the mentally challenged. Psychosocial Rehabilitation Journal, 16, 125-134.

[49] Carter, T.M. (1998). The effects of spiritual practices on recovery from substance abuse. Journal of Psychiatric and Mental Health Nursing, 5(5), 409-413.

[50] Green, S., Higgins, J. P. T., Alderson, P., Clarke, M., Mulrow, C.D., et al. (2008). Chapter 1: What is a systematic review? In: Higgins, J.P.T., Green, S., (Eds). Cochrane handbook for systematic reviews of interventions version. The Cochrane Collaboration. Available: http://www.cochrane-handbook.org/ (accessed12 Dec 2012).

[51] Centre for Reviews and Dissemination. (2008). CRD's guidance for undertaking reviews in health care. York: University of York Press.

[52] Effective Public Health Practice Project. (2009). Quality assessment tool for Quantitative Studies. [http://www.ehpp-ca/PDF/QATool_Dec_2009.pdf] (accessed 12 Abril 2013)

[53] Jackson, N., Waters, E. \& The Guidelines For Systematic Reviews Taskforce. (2004) The challenges of systematically reviewing public health interventions. Journal of Public Health, 26, 303-307.

[54] Thomas J, Sutcliffe K, Harden A, Oakley A, Oliver S, Rees R, Brunton G, Kavanagh J. (2003) Children and Healthy Eating: A systematic review of barriers and facilitators. London: EPPI-Centre, Social Science Research Unit, Institute of Education, University of London. University of London. Available at:

http://eppi.ioe.ac.uk/EPPIWebContent/hp/reports/healthy_eat ing02/Final_report_web.pdf

[55] GRADE Working Group (2004). Grading quality of evidence and strength of recommendations. BMJ. 328,1490-1494.

[56] Smith, L.K. Pope, C., Botha, J.L. (2005) Patients' help-seeking experiences and delay in cancer presentation: a qualitative synthesis. Lancet; 366(9488): 825-31. 
[57] Munro, S., Lewin, S., Smith, H., Engel, M., Fretheim, A., Volmink, J. (2007) Adherence to tuberculosis treatment: a qualitative systematic review of stakeholder perceptions. PLOS Medicine. 4(7): e238.

[58] Heinz, A., Epstein, D. H., Preston, K. L. (2007). Spiritual/Religious experiences and in-treatment outcome in an inner-city program for heroin and cocaine dependence. Journal of Psychoactive Drugs, 39, 41-49.

[59] Miller, W.R., Forcehimes, A., O’Leary, M.J., LaNoue, M. D. (2008). Spiritual direction in addiction treatment: Two clinical trials. Journal of Substance Abuse Treatment. 35, 343-442.

[60] Kelly J.F., Stout, R. L., Magill, M., Tonigan, J.S., Pagano, M. E.(2011). Spirituality in recovery: a lagged mediational analysis of Alcoholics Anonymous' principal theoretical mechanism of behaviour change. Alcsm Clin Exp Res, 35(3), 454-463

[61] Project MATCH Research Group (1993). Project MATCH (Matching Alcoholism Treatment to Client Heterogeneity): rationale and methods for a multisite clinical trial matching patients to alcoholism treatment. Alcohol Clin Exp Res.,17(6),1130-1145.

[62] Zemore, S. E. (2007). A role for spiritual change in the benefits of 12-steps involvement. Alcoholism: Clinic \& Experimental Research, 31(S3), 76S-79

[63] Brown, H., \& Peterson, J. (1991). Assessing Spirituality in Addictions Treatment and Follow-Up: Development of the Brown-Peterson Recovery Progress Inventory (B-PRPI). Alcoholism Treatment Quarterly. 8(2), 21-45.

[64] Maslow, A. H. (1970). Motivation and personality (2nd ed.). New York:

[65] Sterling, R.C., Weinstein, S., Losardo, D., Raively, K., Hill, P., Petrone, A., Gottheil, E., (2007). A retrospective case control study of alcohol relapse and spiritual growth. American Journal on Addictions, 16, 56-61.

[66] Flynn, P. M., Joe, G. W., Broome, K. M., Simpson, D. D., \& Brown, B. S. (2003). Recovery from opioid addiction in DATOS. Journal of Substance Abuse Treatment, 25, 177 186.

[67] Chen, G. (2006). Social support, spiritual program and addiction recovery. International Journal of Offender Therapy and Comparative Criminology, 50, 306-323.

[68] Duvall, J. L., Staton-Tindall, M., Oser, C., \& Leukefeld, C. (2008). Persistence in turning to faith as a predictor of drug use and criminality among drug court clients. Journal of Drug Issues, 38, 1207-1224.

[69] Atkins, R.G., Hawdon, J.E. (2007). Religiosity and participation in mutual-aid support groups for addiction. Journal of Substance Abuse Treatment, 33(3), 321-331.

[70] Zemore, S.E, Kaskutas, L.A. (2004) Helping, spirituality and Alcoholics Anonymous in recovery. J. Stud

[71] Pardini, D.A., Plante, T.G., Sherman, A., Stump, J.E. (2000).
Religious faith and spirituality in substance abuse recovery: determining the mental health benefits. J Subst Abuse Treat, $19,347-354$

[72] Brush, B.L., McGee, E.M. (2000). Evaluating the Spiritual Perspectives of Homeless Men in Recovery. Applied Nursing Research, 13, 181-186

[73] Neff, J.A., MacMaster, S.A. (2005). Spiritual mechanisms underlying substance abuse behaviour change in faith-based substance abuse treatment. Journal of Social Work Practice in the Addictions, 5, 33-54.

[74] Robinson, E.A.R., Krentzman, A.R., Webb, J.R., Browler, K.J. (2011). Six-month changes in spirituality and religiousness in alcoholics predicts drinking outcomes at nine months. J Stud Alcohol Drugs, 72, 660-668.

[75] Piderman, K. M., Schneekloth, T.D., Pankratz, V.S., Maloney, S.D., Atchuler, S.L. (2007). Spirituality in alcoholics during treatments. Am J Addict, 16, 232-237.

[76] Carroll, S. (1993). Spirituality and purpose in life in alcoholism recovery. J Stud Alcohol, 54, 297-301.

[77] Noblejas de la Flor, M.A. (1997). Meaning levels and drug-abuse therapy: An empirical study. International Forum for Logotherapy, 20, 46-51.

[78] Waisburg, J., \& Porter, J. (1994). Purpose in life and outcomes of treatment for alcohol dependence. British Journal of Clinical Psychology, 33, 49-63.

[79] Brush, B., \& Daly, P. (2000). Assessing spirituality in primary care practice: Is there a time?. Clinical Excellence of Nurse Practitioners, 4(2), 67-71.

[80] Galanter, M. (2006). Spirituality and addiction: A research and clinical perspective. American Journal on Addictions, 15(4), 286-292.

[81] Graham, J., Brush, B., \& Andrew, M. (2003). Spiritual care process and content: lesson learned from the ECHO project. Journal of the American Academy of Nurse Practitioners. 15, 473-478.

[82] Sellers, S.C. \& Haag, B.A. (1998). Spiritual nursing interventions. Journal of Holistic Nursing, 16(3), 338-354.

[83] Sherwood, G. (2000). The power of nurse-client encounters. Journal of Holistic Nursing, 18(2), 159-175.

[84] Gilbert, P. (2011). Spirituality and Mental Health: A handbook for service users, carers and staff wishing to bring a spiritual dimension to mental health services. Brighton: Pavilion Publishing.

[85] Volkow, N.D., Wang, G.J., Fowler, J.S., Tomasi, D. (2012). Addiction circuitry in the human brain. Annu Rev Pharmacol Toxicol, 52, 321-336.

[86] Insel, T. (2013, April). Thomas Insel: Towards a new understating of mental health [Video file]. Retrieved from http://www.ted.com/talks/thomas_insel_toward_a_new_under standing_of_mental_illness.html 